\title{
Flora da Bahia: Cannabaceae
}

\section{Anderson Ferreira Pinto Machado ${ }^{1,2^{*}}$, Marcus Felipe Oliveira da Silva ${ }^{3, a}$, Reyjane Patrícia de Oliveira ${ }^{4, b}$, Ana Maria Giuliettit ${ }^{4, c} \&$ Daniela Santos Carneiro Torres ${ }^{4, d}$}

${ }^{1}$ Colégio da Polícia Militar Eraldo Tinoco, Sec-BA, Vitória da Conquista, Bahia, Brasil.

${ }^{2}$ Programa de Pós-Graduação em Ciências Ambientais, Universidade Estadual do Sudoeste da Bahia, Itapetinga, Bahia, Brasil.

${ }^{3}$ Escola Nacional de Botânica Tropical, Instituto de Pesquisa Jardim Botânico do Rio de Janeiro, Rio de Janeiro, Brasil.

${ }^{4}$ Programa de Pós-graduação em Botânica, Departamento de Ciências Biológicas, Universidade Estadual de Feira de Santana, Bahia, Brasil.

Resumo - É apresentada a flora de Cannabaceae do estado da Bahia, Brasil. Foram reconhecidas seis espécies nativas em dois gêneros: Celtis, com quatro espécies (C. brasiliensis, C. ehrenbergiana, C. iguanaea e C. orthacanthos), e Trema, com duas (T. micrantha e T. mollis). São apresentadas chaves de identificação, descrições, ilustrações, mapas de distribuição no estado e comentários para os táxons. Palavras-chave adicionais: Celtis, Brasil, florística, Rosales, Trema.

\begin{abstract}
Flora of Bahia: Cannabaceae) - The flora of Cannabaceae from the state of Bahia is presented. Six native species were recognized in two genera: Celtis, with four species (C. brasiliensis, C. ehrenbergiana, C. iguanaea and C. orthacanthos), and Trema, with two (T. micrantha and T. mollis). Identification keys, descriptions, illustrations, distribution maps in the state and notes on the taxa are presented. Additional key words: Celtis, Brazil, floristics, Rosales, Trema.
\end{abstract}

\section{CANNABACEAE}

Árvores, arbustos eretos ou escandentes, ou ervas, monoicos, dioicos ou polígamos. Ramos armados ou inermes, retos ou em zigue-zague; estípulas aos pares, laterais ou interpeciolares. Folhas alternas ou raramente opostas; lâmina simples, até fortemente palmado-lobada ou composta, margens crenadas, crenuladas, denteadas, serreadas, serrilhadas ou raramente inteiras. Inflorescências axilares em cimeiras, racemos ou panículas, ou flores pistiladas isoladas. Flores unissexuadas ou mais raramente bissexuadas, actinomorfas, monoclamídeas; sépalas (2-)4-8(9), livres ou ligeiramente unidas na base. Flores estaminadas geralmente isostêmones; estames opostos às sépalas, anteras bitecas, rimosas, grãos de pólen 3(2)-porados; pistilódio raramente presente. Flores pistiladas com gineceu (1)2-carpelar, sincárpico; ovário súpero, 1(2)locular, uniovulado, placentação apical, estiletes 2, estigmas lobados, bifurcados ou raramente inteiros. Frutos drupas, sâmaras (em Parasponia Miq.) ou aquênios (Cannabis L. e Humulus L.).

Cannabaceae está inserida na ordem Rosales e seus representantes estiveram historicamente associados a famílias como Moraceae, Urticaceae e Ulmaceae, as quais compõem um clado bem sustentado (APG IV 2016; Sun et al. 2016). Kubitzki (1993) incluiu apenas os gêneros Cannabis e Humulus em Cannabaceae, por

\footnotetext{
*Autor para correspondência: machadoafp@gmail.com;

amarcusfoliveira@gmail.com; brpatricia@uefs.br;

cagiuliettiharley@gmail.com; dscarneiro@hotmail.com;

Editor responsável: Alessandro Rapini

Submetido: 3 dez. 2018; aceito: 26 jun. 2019

Publicação eletrônica: 10 jul. 2019; versão final: 18 jul. 2019
}

serem ervas com frutos do tipo aquênio, ambos distribuídos nas regiões temperadas do hemisfério norte. Em Ulmaceae, Todzia (1993) incluiu 18 gêneros e cerca de 100 espécies de árvores ou arbustos com frutos do tipo drupa ou sâmara. Com base em estudos químicos, morfológicos e filogenéticos, oito gêneros foram transferidos da subfamília Celtidoideae (Ulmaceae) para Cannabaceae (Giannasi 1978; Wiegrefe et al. 1998; Yang et al. 2013).

$\mathrm{Na}$ atual circunscrição, Cannabaceae inclui 10 gêneros e cerca de 100 espécies de árvores, arbustos, lianas e ervas distribuídas nas regiões tropicais e temperadas do mundo todo (Yang et al. 2013; Stevens 2015). Destacamse economicamente na família a maconha ou cânhamo (Cannabis sativa L.), cultivada para fins alimentares, medicinais e para a extração de óleos e fibras têxteis (Oomah et al. 2002; Callaway 2004; Zuardi et al. 2006), e o lúpulo (Humulus lupulus L.), usado na fabricação de cervejas (Zanoli \& Zavatti 2008).

Para o Brasil, Carauta (1974) reconheceu 12 espécies de Ulmaceae s.l. (incl. Cannabaceae), três delas representadas na Bahia. Porém, na Flora do Brasil (2020, em construção), Cannabaceae e Ulmaceae são tratadas separadamente. De acordo com essa recente classificação, Ulmaceae inclui dois gêneros no país, Ampelocera Klotzsch, com quatro espécies, e Phyllostylon Capan. ex Benth. \& Hook.f., com duas espécies, sendo A. glabra Kuhlm. e $P$. brasiliensis Capan. ex Benth. \& Hook.f. reconhecidas para a Bahia (Machado 2019). Para Cannabaceae, são referidos os gêneros Celtis L., com cinco espécies, e Trema Loureiro, apenas com T. micrantha (L.) Blume (Machado \& Silva 2019). No presente trabalho, esses dois gêneros são citados para a Bahia, onde ocorrem quatro espécies de Celtis e duas de Trema. 


\section{Chave para os gêneros}

1. Ramos em zigue-zague, armados; margens das folhas recortadas a partir da metade superior ou um pouco acima da base, crenuladas, crenadas, denteadas a serreadas, raramente inteiras; anteras extrorsas; drupas ovais a elípticas (4-25 mm diâm.)

1. Celtis

1'. Ramos retos a recurvados, inermes; margens das folhas recortadas desde a base, serreadas, serrilhadas ou denteadas; anteras introrsas; drupas arredondadas (2-4 mm diâm.) 2. Trema

\section{Celtis L.}

Árvores ou arbustos eretos ou escandentes. Ramos em zigue-zague, espinescentes, raramente inermes, espinhos retos ou curvos; estípulas interpeciolares, livres, caducas. Folhas alternas; lâmina oval a elíptica, cartácea a coriácea, ápice agudo a obtuso, base simétrica ou assimétrica, obtusa, arredondada a cordada, margens recortadas a partir da metade superior ou um pouco acima da base, crenuladas, crenadas, denteadas, serreadas, raramente inteiras, venação actinódroma, nervuras 3(5), pontuações evidentes devido à base dos tricomas, geralmente com domácias marsupiformes. Inflorescências cimeiras; brácteas inconspícuas, caducas; flores estaminadas numerosas, em glomérulos congestos em toda a extensão do ramo; flores pistiladas 1-3, no ápice dos ramos. Flores estaminadas pediceladas; receptáculo piloso; sépalas (4)5, ovais, pilosas, margens ciliadas; estames 5, filetes retos ou curvos no botão, eretos na flor aberta, anteras extrorsas, dorsifixas; pistilódio colunar, vestigial ou ausente. Flores pistiladas pediceladas; receptáculo piloso; sépalas 4(5), ovais, pilosas, margens ciliadas; estaminódios 5, decíduos; ovário séssil, 1-locular, estigmas bifurcados. Drupas pouco carnosas, ovais a elípticas, glabras ou pilosas, amarelas, alaranjadas, vermelhas ou arroxeadas na maturidade; sementes brancas ou bege.

Celtis inclui entre 70 e 100 espécies, com distribuição em regiões tropicais e temperadas do mundo (Todzia 1993; Martins \& Pirani 2009; Pederneiras et al. 2011; Yang et al. 2013). O número de espécies é considerado duvidoso, devido à grande plasticidade fenotípica observada nos complexos de espécies (Todzia 1993; Sattarian 2006; Yang et al. 2013).

As cinco espécies registradas para o Brasil (Machado \& Silva 2019) são incluídas em Celtis subg. Mertensia Planch. (Berg \& Dahlberg 2001). A identificação de alguns materiais da Bahia sob $C$. chichape (Weed.) Miq., como observado no Species Link, é aqui considerada equivocada, uma vez que, segundo Machado \& Silva (2019), a ocorrência dessa espécie no Brasil é restrita ao Rio Grande do Sul e Santa Catarina.

\section{Chave para as espécies}

1. Ramos arroxeados, glabros ou com indumento apenas na base dos espinhos e nós

1.4. C. orthacanthos

1'. Ramos esbranquiçados, amarronzados ou ferrugíneos, indumento distribuído na porção distal dos ramos

2. Espinhos recurvados; drupas 12-15 mm compr. . 1.3. Celtis iguanaea

2'. Espinhos retos, levemente curvados ou ausentes; drupas 4-10 mm compr.

3. Lâmina foliar 3,5-10 cm compr., margens serreadas a denteadas, face adaxial escabra; drupas 8-10 mm compr.

1.1. C. brasiliensis

3'. Lâmina foliar 2-3 cm compr., margens crenadas, crenuladas, denteadas a raramente quase inteiras, face adaxial adpressopubérula; drupas 4-5 mm compr. .................

\subsection{C. ehrenbergiana}

1.1. Celtis brasiliensis (Gardner) Planch., Ann. Sci. Nat. Bot., sér. 3. 10: 310. 1848.

Figuras $1 \mathrm{~A}-\mathrm{D}, 2 \mathrm{~A}$ e 3.

Árvores ou arbustos 3-10 $\mathrm{m}$ alt. Ramos jovens pubescentes a tomentoso-ferrugíneos na porção distal, glabrescentes, espinhos 1-2(-3) cm compr., retos ou levemente curvados; estípulas 2-3 mm compr., pubescentes, indumento ferrugíneo a amarelado. Folhas com pecíolo 3-8 $\mathrm{mm}$ compr., pubérulo a tomentoso, glabrescente; lâmina $3,5-10 \times 1-5 \mathrm{~cm}$, cartácea, oval-elíptica, base frequentemente assimétrica, arredondada a cordada, ápice obtuso a agudo, mucronado, margens serreadas a denteadas, face adaxial com pontuações, escabra, tomentosa a glabrescente, face abaxial pubérula, pubescente a tomentoso-ferrugínea, glabrescente, nervuras 3(5), domácias recobertas pelo mesmo indumento da lâmina. Drupas $8-10 \times 7-8 \mathrm{~mm}$, esparsamente pubérulas a glabras.

Celtis brasiliensis ocorre na Argentina, Bolívia, Brasil, Paraguai e Peru (Berg \& Dahlberg 2001). No Brasil, ocorre nas Regiões Nordeste (Bahia), CentroOeste (Distrito Federal, Goiás, Mato Grosso e Mato Grosso do Sul), Sudeste (Espírito Santo, Minas Gerais, Rio de Janeiro e São Paulo) e Sul (Paraná e Santa Catarina) (Machado \& Silva 2019). Foi registrada nos domínios da Floresta Atlântica, Caatinga e Cerrado, em florestas primárias e secundárias, formações de restinga, florestas ombrófilas densas e florestas estacionais semideciduais e deciduais (BFG 2015). Na Bahia ocorre nos domínios fitogeográficos da Caatinga, Cerrado e Mata Atlântica: B7, C6, C7, D2, D/E5, D6, D7, D8, D/E9, E2/3, E6, E7, E8, E9, F6, F7, F8, G4, G5, G6, G7, G8 e H8. Floresce e frutifica durante o ano todo.

Material selecionado - Amargosa, entrada da porteira da fazenda Acaju, 1301'60"S, 39³5'59"W, 27 maio 2005 (fl.), M.A. Costa et al. 06 (ALCB); Boa Nova, Parque Nacional de Boa Nova, 
14²1'46"S, 40¹2'27"W, 2 mar. 2013 (fl.fr.), L.Y.S. Aona 2100 (HUEFS); Brotas de Macaúbas, Nova Vista, 1159'57"S, 42³7'32"W, 3 jun. 2007 (fl.), A.A. Conceição 2225 (HUEFS); Cachoeira, fazenda Paraíso (ex-Favela), 12³7'06"S, 3857'21"W, 8 nov. 2004 (fl.), L.P. Queiroz 9714 (HUEFS); Caém, Serra de

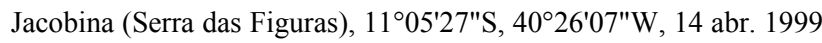
(fl.), L.P. Queiroz 5549 (ALCB, HUEFS); Caetité, ca. $14 \mathrm{~km}$ ao norte de Caetité em direção a Mamiaçu, $14^{\circ} 04^{\prime} 10^{\prime \prime} \mathrm{S}, 42^{\circ} 28^{\prime 2} 29^{\prime \prime} \mathrm{W}$, 12 abr. 2005 (fl.), E.B. Miranda 754 (HUEFS); Carinhanha, Médio São Francisco, $14^{\circ} 18^{\prime} 17^{\prime \prime S}$, 43ํ5'53"W, 25 nov. 2007 (fl.), M.L. Guedes et al. 13970 (ALCB, HUEFS); Catu, próximo a Bela Flor, 12²1'12"S, 38²2'43"W, 13 fev. 1980 (fl., fr.), A.P. Araújo 204 (CEPEC); Conceição do Coité, Serra do Mucambo, $11^{\circ} 30^{\prime} \mathrm{S}$, $39^{\circ} 11^{\prime} \mathrm{W}, 3$ fev. 2013 (fl.), D.N. Carvalho \& A.O. Moraes 187 (HUEFS); Conceição do Jacuípe, Paraguaçu, $12^{\circ} 18^{\prime} 60^{\prime \prime} \mathrm{S}$, 3845'59"W, 1 maio 1995 (fl., fr.), A.J. Ribeiro s.n. (ALCB 28578); Contendas do Sincorá, FLONA, ao lado da sede, $13^{\circ} 45^{\prime} 47^{\prime \prime} \mathrm{S}$, 4102'27"W, 6 ago. 2008 (fr.), S.L. Cunha-Silva 64 (HUESB); Entre Rios, Litoral Norte, arredores, $11^{\circ} 56^{\prime} 31^{\prime \prime S}, 38^{\circ} 05^{\prime} 03^{\prime \prime} \mathrm{W}, 18$ out. 1981 (fl.), G. Hatschbach 44302 (ALCB); Feira de Santana, Distrito de Humildes, $12^{\circ} 16^{\prime} 01^{\prime \prime S}, 38^{\circ} 58^{\prime} 00^{\prime \prime W}, 26$ jun. 2012 (fl.),

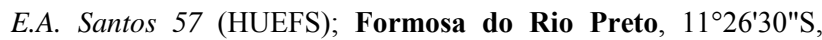
45¹6'11"W, 30 mar. 2000 (fl.), E.B. Miranda Silva et al. 364 (ALCB, CEPEC, HUEFS); Iaçu, Lage Preta, 1246'03"S, $40^{\circ} 12^{\prime} 41^{\prime \prime W}, 12$ mar. 2005 (fl.), F. França 5150 (HUEFS); Irecê, $11^{\circ} 18^{\prime} 16^{\prime \prime} \mathrm{S}, 41^{\circ} 51^{\prime} 20^{\prime \prime} \mathrm{W}, 26$ out. 2009 (fl.), M.L. Guedes et al. 16168 (ALCB, HUEFS); Itaeté, Paraguaçu, 1259'12"S, 40 58'20"W, 13 abr. 2001 (fl.), D.L. Santana 240 (ALCB); Itagibá, Litoral Sul, Mata do Laterítico, $14^{\circ} 17^{\prime} 02^{\prime \prime S}, 39^{\circ} 50^{\prime} 33^{\prime \prime W}, 13$ jul. 2009 (fl.), M.L. Guedes et al. 16355 (ALCB, NY); Itatim, Morro

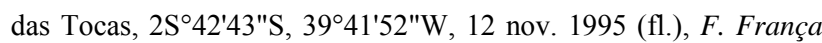

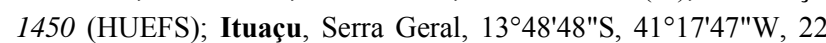
dez. 1983 (fl., fr.), E.P. Gouveia 02/83 (ALCB); Jacobina, 22 km a partir da sede, estrada para Itaitu, $11^{\circ} 10^{\prime} 01 " \mathrm{~S}, 40^{\circ} 30^{\prime} 59^{\prime \prime} \mathrm{W}, 21 \mathrm{fev}$. 1993 (fr.), A.M. Amorim 995 (CEPEC, NY); Jaguarari, fazenda Olho d'Água, $10^{\circ} 15^{\prime} 50^{\prime \prime S}, 40^{\circ} 11^{\prime} 45^{\prime \prime} \mathrm{W}, 22$ maio 1972 (fr.), F.B. Ramalho 114 (HUEFS); Juazeiro, Serra do Mulato, 09²4'43"S, 40²9'55"W, 27 mar. 2000 (fl.), N.G. Jesus et al. 894 (ALCB, CEPEC, HUEFS, HUESB); Jussari, RPPN Serra do Teimoso, 15¹1'30"S, 39²9'42"W, 21 nov. 1998 (fl.), A.M. Amorim 2688 (CEPEC, NY); Licínio de Almeida, trilha Lameirão, 14²40'57"S, 42³0'26"W, 22 fev. 2014 (fl.), N. Roque et al. 4171 (ALCB); Maracás, estrada para Marcionílio Souza, 1326'28"S, 40²5'50"W, 3 nov. 2011 (fl.), E. Melo 10562 (HUEFS); Morro do Chapéu, Buraco da Duda, $11^{\circ} 33^{\prime} 01^{\prime \prime S}, 41^{\circ} 09^{\prime} 22^{\prime \prime W}, 12$ jul. 2008, E. Melo 5904 (HUEFS); Mundo Novo, Paraguaçu, fazenda Aliança,

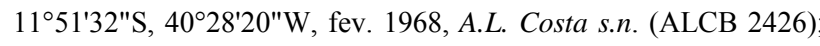
Piatã, margem do Rio de Contas, $13^{\circ} 09^{\prime} 07^{\prime \prime S}, 41^{\circ} 46^{\prime} 21^{\prime \prime} \mathrm{W}, 18$ abr. 2014 (fl.), E. Melo 12607 (HUEFS); Pindobaçu, Piemonte da Diamantina, margem direita do rio Itapicuru-açu, $10^{\circ} 43^{\prime} 60^{\prime \prime S}$, 40²0'59"W, 20 dez. 1999 (fl.), M.L. Guedes et al. 6975 (ALCB); São Desidério, BR-135, 12²1'48"S, 4458'23"W, 2 set. 2007 (fr.), R.M. Santos 1755 (HUEFS); São Gabriel, estrada para Jussara,

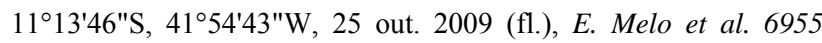
(ALCB, HUEFS); Seabra, 12²5'07"S, 41 ${ }^{\circ} 46^{\prime} 13^{\prime \prime W}, 27$ jan. 1998 (fl.), A.M. Amorim 2182 (CEPEC, NY); Senhor do Bonfim, Piemonte da Diamantina, $10^{\circ} 27^{\prime} 41^{\prime \prime S}, 40^{\circ} 11^{\prime} 22^{\prime \prime W}, 12$ jan. 2006, P.E. Mattos-Andrade s.n. (ALCB 80876a); Serra Preta, $7 \mathrm{~km}$ a W do Ponto de Serra Preta, 1209'38"S, 39¹9'54"W, 17 jul. 1985 (fl.),
L.R. Noblick 4171 (CEPEC); Tanhaçu, ponte sobre o Rio de Contas, $14^{\circ} 01^{\prime} 17^{\prime \prime} \mathrm{S}, \quad 41^{\circ} 14^{\prime} 53^{\prime \prime} \mathrm{W}, 24$ fev. 2013 (fr.), A.F.P. Machado \& A.K.A. Santos 1158 (HUEFS); Umburanas, Distrito de Delfino, 1043'58"S, 41 ${ }^{\circ} 19^{\prime} 35^{\prime \prime} \mathrm{W}, 24$ maio 2008 (fl.), E. Melo 5734 (HUEFS).

Celtis brasiliensis pode ser confundida com $C$. iguanaea (Jacq.) Sarg., quando suas folhas são pequenas e não há frutos. No entanto, C. brasiliensis apresenta espinhos retos ou levemente curvados (vs. recurvados em C. iguanaea); a lâmina foliar possui face adaxial escabra, tomentosa a glabrescente (vs. esparsamente pubérula a glabra), pontuações visíveis (vs. ausentes) e domácias pubescentes (vs. glabras), além das drupas menores que $10 \mathrm{~mm}$ de comprimento quando maduras (vs. 12-15 mm compr.). Variações nesses caracteres podem ocorrer nas duas espécies. Por exemplo, o espécime Amorim 995, identificado como C. brasiliensis, apresenta a lâmina foliar com face adaxial tomentosa, por isso suas pontuações não são visíveis, enquanto Harley 16213, identificado como $C$. iguanaea, apresenta a lâmina foliar com face adaxial escabra e pontuações visíveis. Os demais caracteres indicados, no entanto, são consistentes para a separação dessas espécies.

Segundo Romanczuk \& Martinez (1978), C. brasiliensis é sinônimo de C. pubescens (Kunth) Spreng, porém Berg \& Dahlberg (2001) consideram C. pubescens sinônimo de C. iguanaea. Após análise dos espécimes-tipo como parte do presente trabalho, decidiu-se por considerar C. brasiliensis um nome aceito.

\subsection{Celtis ehrenbergiana (Klotzsch) Liebm., Dansk.} Vidensk. Selsk. Skrift. 5(2): 339. 1851.

Figuras 1E-H, 2B e 4.

Árvores ou arbustos, 3-8 m alt. Ramos jovens com indumento pubérulo-esbranquiçados a amarronzados na porção distal, glabrescentes, espinhos $1(-3) \mathrm{cm}$ compr., retos, levemente curvados ou ausentes; estípulas 2-4 mm compr., pubescentes. Folhas com pecíolo 2-8 $\mathrm{mm}$ compr., pubérulo, glabrescente; lâmina $2-3 \times 0,5-3 \mathrm{~cm}$, cartácea a coriácea, elíptica, oblonga ou oval a raramente lanceolada, base geralmente simétrica, truncada, arredondada a cordada, ápice obtuso, agudo, acuminado, margens crenadas, crenuladas, denteadas ou raramente quase inteiras, ambas as faces com pontuações, esparsamente adpresso-pubérulas principalmente nas nervuras principais, raro tomentosas, glabrescentes, nervuras $3(-6)$, domácias recobertas pelo mesmo indumento da lâmina. Drupas 4-5 × 3-4 $\mathrm{mm}$, esparsamente pubérulas a glabras.

Celtis ehrenbergiana ocorre na Argentina, Bolívia, Brasil, Estados Unidos, Haiti, México, Paraguai, Porto Rico e Uruguai (Berg \& Dahlberg 2001). No Brasil, ocorre nas Regiões Nordeste (Bahia, Ceará e Paraíba), Centro-Oeste (Goiás, Mato Grosso e Mato Grosso do Sul) e em todos os estados das Regiões Sudeste e Sul (Machado \& Silva 2019). Foi registrada nos domínios 

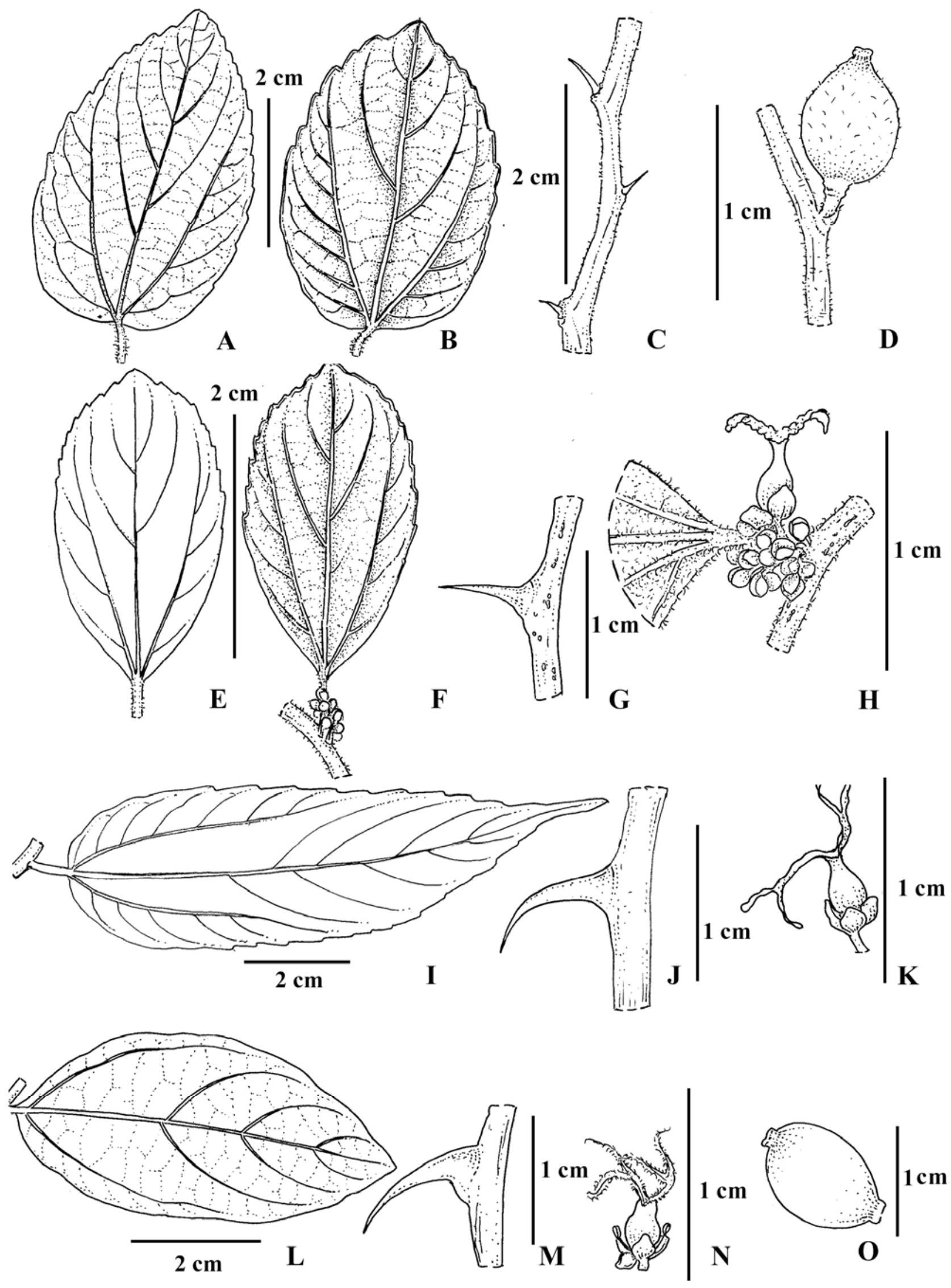

Figura 1. A-D. Celtis brasiliensis: A- folha, face adaxial; B- folha, face abaxial; C- ramo com espinhos; D- fruto. (França 5150). E-H. C. ehrenbergiana: E- folha, face adaxial; F- folha, face abaxial; G- detalhe do espinho; H- inflorescência mostrando uma flor pistilada e as estaminadas congestas (Carvalho 1935). I-K. C. iguanaea: I- folha, face abaxial; J- detalhe do espinho; K- flor pistilada (Amorim 4475). L-O. C. orthacanthos: L- folha, face adaxial; M- detalhe do espinho; N- flor pistilada; O- fruto (Hage 2064). 

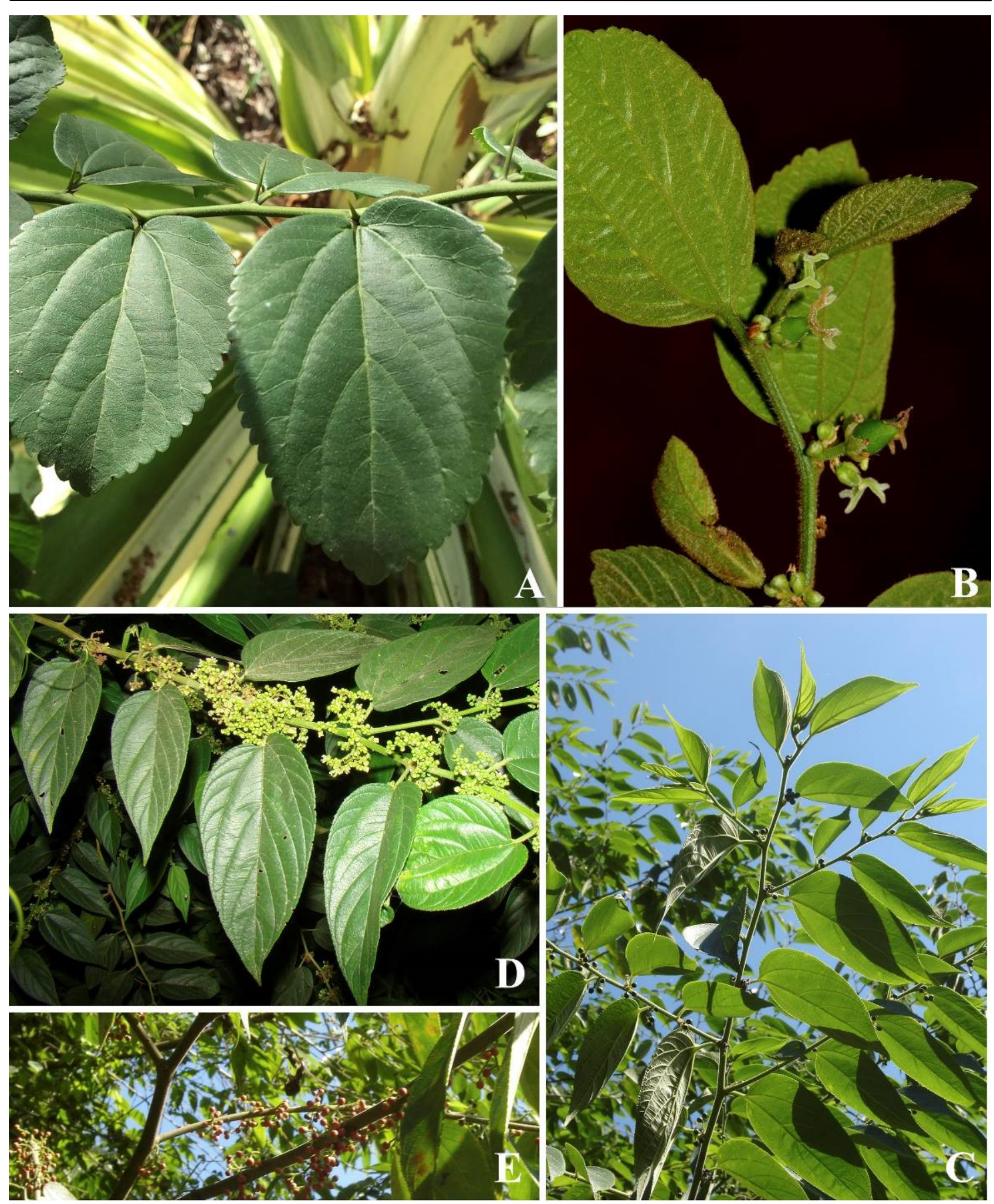

Figura 2. A. Celtis brasiliensis: ramo com folhas e espinhos; B. C. ehrenbergiana: ramo com folhas, flores pistiladas e frutos jovens (foto: C.O. Azevedo). C-E. Trema micrantha: C- ramo (foto: M.D.M. Vianna f.); D- ramo com folhas e inflorescências (foto: L. Pederneiras); E- ramo com frutos (foto: M.D.M. Vianna f.).

da Floresta Atlântica, Cerrado e Pantanal (BFG 2015, Machado \& Silva 2019). Na Bahia, habita florestas primárias e secundárias, em formações de floresta ombrófila densa e floresta estacional semidecidual: $\mathbf{C 7}$, D4, D6, D7, E7, E8, F4, F6, F7, G7 e H8. Floresce e frutifica durante $\mathrm{o}$ ano todo.

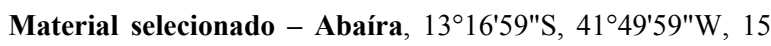
out. 1992 (fl.), W. Ganev 1222 (ALCB, NY); Anguera, 6 km a leste de Serra Preta, estrada para Anguera, $12^{\circ} 10^{\prime} 33^{\prime \prime S}, 39^{\circ} 16^{\prime} 22^{\prime \prime} \mathrm{W}, 11$ nov. 2004 (fl.), L.P. Queiroz 9716 (HUEFS); Barra, 11 ${ }^{\circ} 5^{\prime 22}$ "S, 4308'29"W, 17 nov. 2007 (fl.), M.L. Guedes et al. 14507 (ALCB); Bom Jesus da Lapa, Rio das Rãs, $12^{\circ} 15^{\prime}$ S, $40^{\circ} 22^{\prime}$ W, 15 fev. 1991 


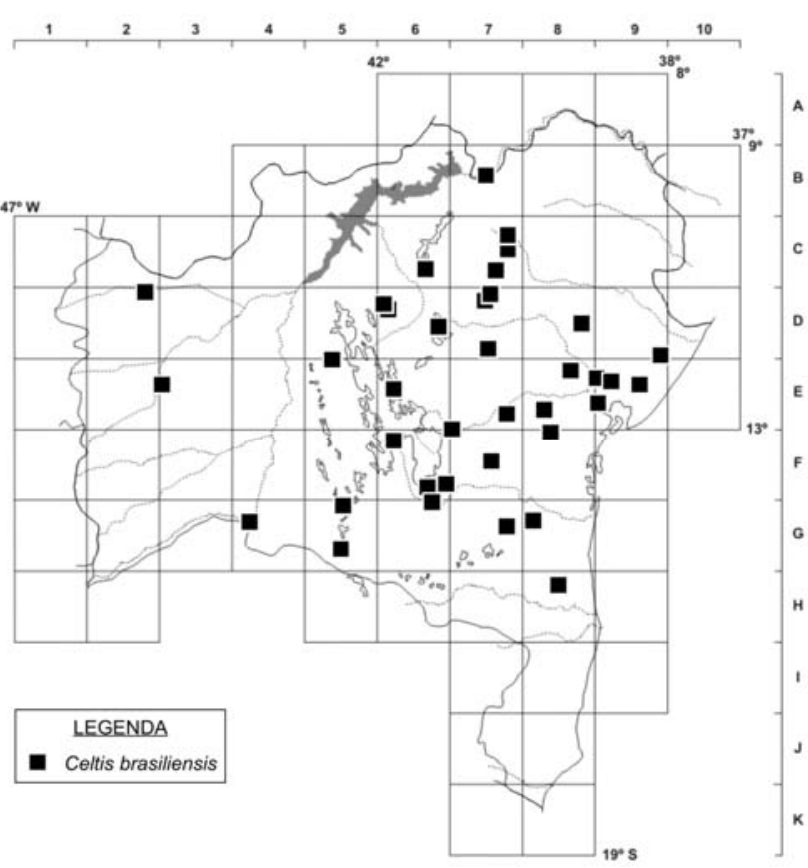

Figura 3. Distribuição geográfica de Celtis brasiliensis no estado da Bahia.

(fr.), G. Hatschbach et al. 55189 (CEPEC, MBM); Campo Formoso, Morro do Salomão/Povoado de Poços, 10³0'27"S, 40¹9'17"W, 26 nov. 2006 (fl.), J.G. Freitas 74 (HUEFS); Ipuaçu, Monte Alto, 12॰13'53"S, 39॰04'38"W, 30 set. 2003 (fl.), C.F. Lucca 17 (CEPEC); Itaju do Colônia, estrada Itaju do Colônia a Santa Cruz da Vitória, 1508'33S", 3943'28W", 2 dez. 2010 (fl., fr.), T.S. Santos 395 (CEPEC, ESA); Itatim, Morro do Agenor, 12 42 'S, 3946'W, 29 set. 1996 (fl.), F. França et al. 1869 (ALCB); Jequié, Km 36 da estrada Jequié-Contendas do Sincorá, 1351'27"S, 4005'01"W, jan. 1999 (fr.), A.M. Carvalho 1935 (CEPEC); Lafaiete Coutinho, 13¹4'19"S, 4006'07"W, 19 maio 2002 (fl., fr.), L.C. Senra et al. 25 (HUEFS, HUESB); Lajedinho, $12^{\circ} 21^{\prime} 21 " \mathrm{~S}, 40^{\circ} 54^{\prime} 20^{\prime \prime} \mathrm{W}, 9$ out. 1987 (fr.), G.E.L. Macedo et al. 2379 (HUESB); Maracás, fazenda Tanquinho, 1326'28"S, 40²5'51"W, 30 jun. 1996 (fl., fr.), L.P. Queiroz 3257 (CEPEC, HUEFS); Miguel Calmon, estrada Miguel Calmon para Cabeceiras, 11²1'33"S, 40³3'52"W, 6 abr. 2001 (fr.), H.P. Bautista 3045 (CEPEC, HUEFS); Morro do Chapéu, estrada Morro do Chapéu-Irecê, $11^{\circ} 30^{\prime} 23^{\prime \prime S}, 41^{\circ} 18^{\prime} 17^{\prime \prime W}, 26$ set. 2004 (fl.), E.L. Borba 2044 (HUEFS); Mucugê, Passagem Funda, 1306'11"S, 41 26'01"W, 17 jul. 1996 (fl.), H.P. Bautista et al. PCD 3716 (ALCB, HUEFS); Poções, 14³1'47"S, 40²1'54"W, 7 fev. 2004 (fl.), W.W. Thomas et al. 13956 (CEPEC); Ruy Barbosa, 12 ${ }^{\circ} 15^{\prime} \mathrm{S}, 40^{\circ} 22^{\prime} \mathrm{W}, 29$ jan. 1993 (fr.), J.A. Kallunki \& J.R. Pirani 396 (CEPEC, NY); Senhor do Bonfim, Carrapichel, $10^{\circ} 22^{\prime} 55^{\prime \prime S}, 40^{\circ} 12^{\prime} 18^{\prime \prime} \mathrm{W}, 19$ maio 2004 (fr.), V.J. Santos 306 (HUEFS); Tanquinho, 11 ${ }^{\circ} 58^{\prime} 43^{\prime \prime S}, 39^{\circ} 06^{\prime} 14^{\prime \prime W}, 24$ nov. 1991 (fl.), I.C. Crepaldi 8 (HUEFS); Vitória da Conquista, matinha da UESB, 1451'58"S, 4050'22"W, 1 nov. 2010 (fl.), A.F.P. Machado et al. 1017 (HUEFS).

Celtis ehrenbergiana pode ser confundida com $C$. brasiliensis quando apresenta lâminas foliares menores, com pontuações e domácias conspícuas e espinhos retos (ou levemente curvados), mas pode ser diferenciada pela face adaxial das lâminas foliares adpresso-pubérula (vs. escabras) e pelos frutos menores (4-5 mm compr. vs. 8-10 mm compr.).

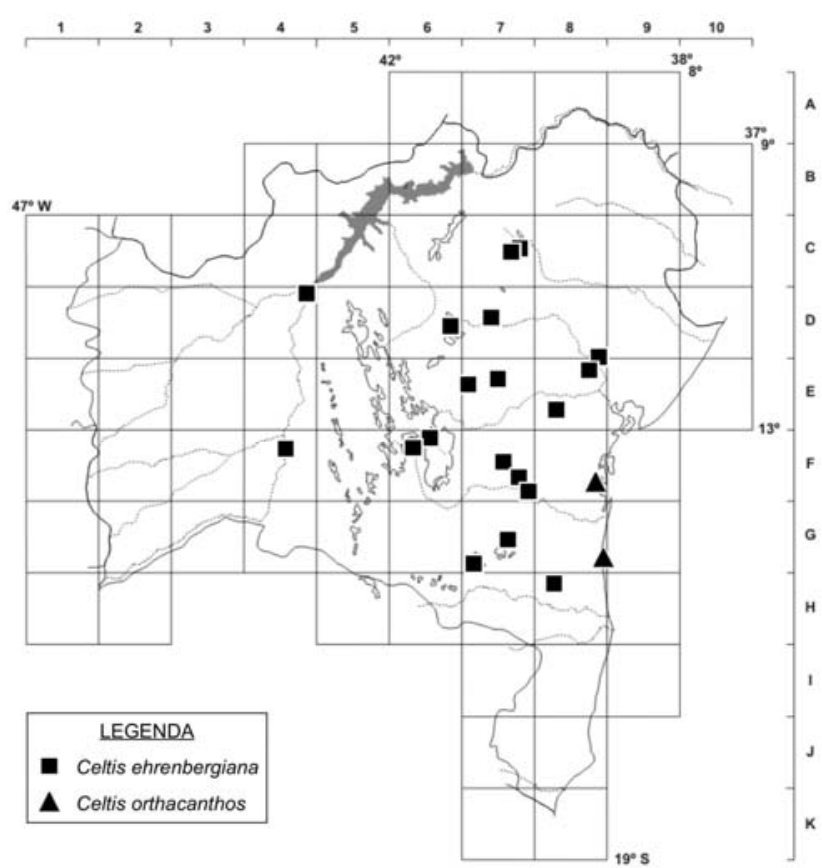

Figura 4. Distribuição geográfica de Celtis ehrenbergiana e C. orthacanthos no estado da Bahia.

1.3. Celtis iguanaea (Jacq.) Sarg., Silva 7: 64. 1895.

Figuras $1 \mathrm{I}-\mathrm{K}$ e 5.

Arbustos escandentes, 4-6 m alt. Ramos jovens pubérulo-esbranquiçados na porção distal, glabrescentes, espinhos $0,5(-1)$ cm compr., recurvados; estípulas 2-4 mm compr., pubérulo-esbranquiçadas. Folhas com pecíolo 5-15 $\mathrm{mm}$ compr., pubérulo, glabrescente; lâmina $3-12 \times 2-8 \mathrm{~cm}$, cartácea a coriácea, oval-elíptica a oval-oblonga, base ligeiramente assimétrica, arredondada a cordada, ápice acuminado, margens crenadas, serreadas ou denteadas, face adaxial geralmente sem pontuações, esparsamente pubérula a glabra, raramente escabra, glabrescente, bulada, face abaxial esparsamente adpresso-pubérula a pilosa nas nervuras principais, glabrescente, raro densamente tomentosa, nervuras 3(-5), domácias glabras e membranáceas. Drupas $12-15 \times 8-10 \mathrm{~mm}$, esparsamente adpresso-pubérulas.

Celtis iguanaea tem distribuição neotropical (Berg \& Dahlberg 2001). No Brasil, tem ocorrência registrada para todos os estados brasileiros e habita diversos tipos de ambientes em todos os domínios fitogeográficos, porém é mais frequentemente encontrada na Floresta Atlântica (BFG 2015; Machado \& Silva 2019). Na Bahia, ocorre em floresta ciliar ou galeria, floresta estacional semidecidual e floresta ombrófila: A/B8, B6, B7, C5, C6, C7, C8, C9, D2, D4, D5, D6, D7, D8, D9, E2/3, E3, E5, E6, E7, E8, E9, F3, F4, F5, F6, F7, F8, G3, G4, G5, G7, G8, H8, I8 e J8. Floresce e frutifica durante o ano todo.

Material selecionado - Abaíra, Chapada Diamantina, 13¹6'59"S, 4149'59"W, 1 nov. 2014 (fl.), M.L. Guedes et al. 22801 (ALCB); Alagoinhas, Campus II/UNEB, 1207'20"S, 38 48'10"W, 30 dez. 2003 (fl.), N.G. Jesus et al. 1991 (HUEFS); Alcobaça, Km 5-8 da BA-001, $17^{\circ} 13^{\prime} \mathrm{S}, 39^{\circ} 12^{\prime} \mathrm{W}$, s.d. (fl.) A.J. 


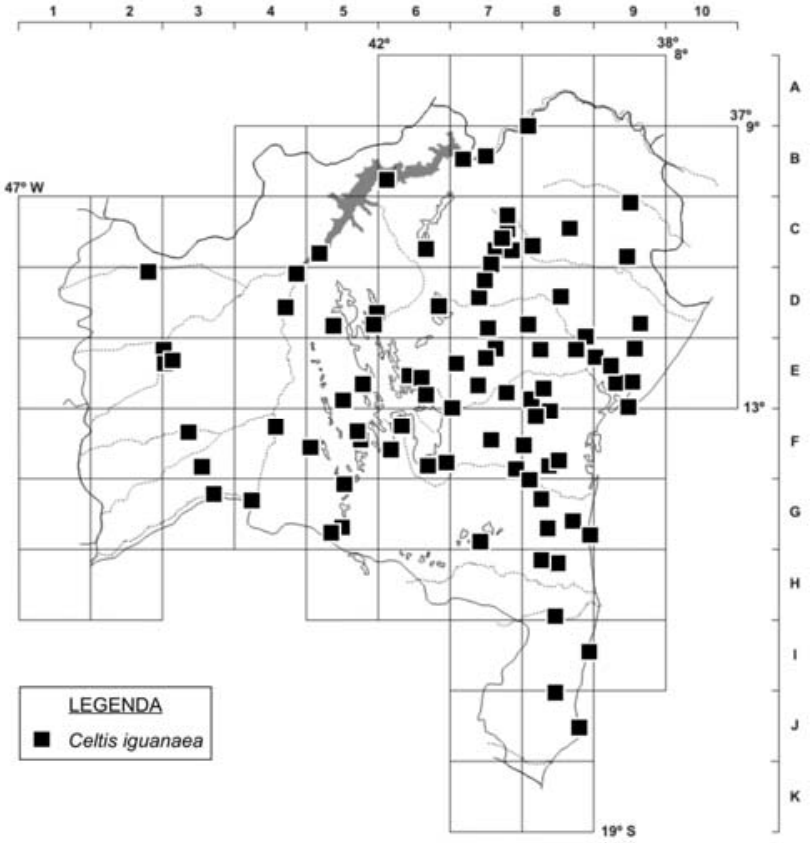

Figura 5. Distribuição geográfica de Celtis iguanaea no estado da Bahia.

Ribeiro 20 (CEPEC); Almadina, rodovia Almadina-Ibitupã, 1444'06"S, 3941'46"W, 15 jan. 1998 (fr.), J.G. Jardim 1246 (CEPEC); Amargosa, Recôncavo Sul, entrada da porteira da fazenda Acaju, $13^{\circ} 01^{\prime} \mathrm{S}, 39^{\circ} 36^{\prime} \mathrm{W}, 27$ maio 2005 (fr.), M.A. Costa \& M.L. Guedes 17 (ALCB); Amélia Rodrigues, 12²3'30"S, 3845'24"W, 23 mar. 1994 (fl., fr.), F. França 955 (HUEFS); Andaraí, rodovia Andaraí-Lençóis, BA-142 Km 14, 1248'26"S, 41¹9'53"W, 22 maio 1989 (fr.), L.A. Mattos-Silva 2834 (CEPEC, HUEFS, MBM); Anguera, fazenda Retiro, $12^{\circ} 09^{\prime} 42^{\prime \prime S}$, 39¹1'02"W, 22 maio 2007 (fr.), D. Cardoso 1932 (HUEFS, NY); Antônio Gonçalves, 10³6'16"S, 40 ${ }^{\circ} 16^{\prime} 14 " \mathrm{~W}, 12$ abr. 2006 (fr.), E. Melo et al. 4379 (HUEFS, HUESB); Barra, Icatu, caminho para Coxos, 1048'25"S, 4249'59"W, fev. 1997 (fl., fr.), L.P. Queiroz 4859 (HUEFS, IAC); Barra do Choça, BR-116 para São Sebastião, 1452'52"S, 40³4'46"W, 21 nov. 1978 (fl.), S.A. Mori 11262 (CEPEC, NY); Barra do Mendes, ca. $27 \mathrm{~km}$ na estrada de terra para Seabra, 1201'13"S, 41 ${ }^{\circ} 59^{\prime} 58^{\prime \prime} \mathrm{W}, 16 \mathrm{dez} .2009$ (fr.), E. Melo et al. 7584 (ALCB, HUEFS); Barreiras, $12^{\circ} 09^{\prime} 10^{\prime \prime} \mathrm{S}, 4^{\circ} 59^{\prime} 24^{\prime \prime} \mathrm{W}, 6$ mar. 1971 (fr.), H.S. Irwin 31636 (UB); Boa Vista do Tupim, 12²7'S, 40³3'W, 9 dez. 1987 (fl., fr.), L.P. Queiroz 1782 (HUEFS, $\mathrm{NY}$ ); Bom Jesus da Lapa, Morro de Bom Jesus, $13^{\circ} 15^{\prime} 32^{\prime \prime} \mathrm{S}$, 40²5'11"W, 15 maio 2001 (fl., fr.), F. França 3544 (HUEFS); Brejões, 1258'59"S, 3955'59"W, 1 jun. 1984 (fr.), J.E.M. Brazão \& C.G. Oliveira 348 (HUEFS); Cachoeira, Porto Castro Alves, 12³1'59"S, 39॰04'59"W, maio 1980 (fl., fr.), Grupo Pedra do Cavalo 83 (ALCB, CEPEC, HUEFS); Caetité, 140.'10"S, 42²8'30"W, 16 dez. 2009 (fr.), L.J. Alves 76 (HUEFS); Carinhanha, Médio São Francisco, a $1 \mathrm{~km}$ do rio Carinhanha,

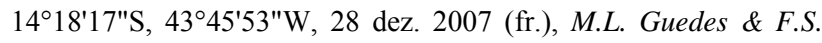
Gomes 14080 (ALCB, HUEFS); Catolândia, 12॰19'06"S, 4451'39"W, 24 jan. 2010 (fr.), K. Yoshida-Arns 24 (HUEFS); Caturama, estrada para Caieiras, entroncamento para Mateus, 13ำ1'46"S, 42 $14^{\prime} 37^{\prime \prime W}, 4$ jul. 2007 (fr.), A.A. Conceição 2330 (HUEFS); Contendas do Sincorá, ca. $3 \mathrm{~km}$ às margens do rio Sincorá, $13^{\circ} 45^{\prime} 46^{\prime \prime} \mathrm{S}, 41^{\circ} 02^{\prime} 28^{\prime \prime W}, 28$ fev. 2000 (fl., fr.), M.M. Silva-
Castro 330 (HUEFS, IAC); Coribe, na estrada para a cidade,

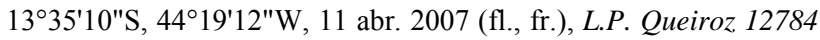

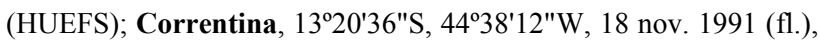
R.F. Vieira 1159 (CEN); Curaça, 08 59'26"S, 3954'33"W, 17 abr. 2015 (fr.), E.D.S. Almeida 4 (HVASF); Feira da Mata, foz do rio Carinhanha, $14^{\circ} 20^{\prime} 11^{\prime \prime S}, 43^{\circ} 47^{\prime} 04^{\prime \prime W}, 26$ maio 2007 (fr.), M.L.S Guedes 13550 (HUEFS); Feira de Santana, periferia do povoado de São Roque, 12¹3'53"S, 3852'29"W, 11 maio 2010 (fr.), $M$. Silva 41 (HUEFS); Filadélfia, $5 \mathrm{~km}$ na estrada para Pindobaçu, $10^{\circ} 44^{\prime} 34 " \mathrm{~S}, 40^{\circ} 07^{\prime} 55^{\prime \prime W}, 28$ fev. 2000 (fl., fr.), A.M. Giulietti \& R.M. Harley 1884 (HUEFS, IAC); Formosa do Rio Preto, Várzea

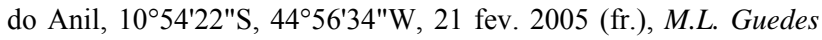
\& A.B. Xavier 11614 (ALCB); Gandu, 1344'38"S, 39²9'12"W, 9 dez. 1972 (fl.), R.S. Pinheiro 2009 (CEPEC, HUEFS, MBM); Iaçu, Morro da Garrafa, 22 fev.1997 (fl., fr.), E. Melo et al. 2061 (HUEFS, IAC); Ibipeba, Aleixo, 42 ${ }^{\circ} 04^{\prime} \mathrm{S} 11^{\circ} 43^{\prime} \mathrm{W}, 4$ abr. 1984 (fl., fr.), H.P. Bautista 931 (ALCB, CEPEC, HUEFS, MBM); Ibipitanga, rio Paramirim, 12 ${ }^{\circ} 43^{\prime} 07^{\prime \prime} \mathrm{S}, 42^{\circ} 30^{\prime} 33^{\prime \prime} \mathrm{W}, 11$ out. 2007 (fl., fr.), A.A. Conceição 2562 (ALCB, HUEFS); Ibiraba, ca. $50 \mathrm{~km}$ de Barra, na margem do rio Icatu, $10^{\circ} 47^{\prime} 30^{\prime \prime} \mathrm{S}, 42^{\circ} 49^{\prime} 02^{\prime \prime} \mathrm{W}, 14 \mathrm{dez}$. 2000 (fl.), L.P. Queiroz 6447 (HUEFS); Ibitiara, estrada lbitiara

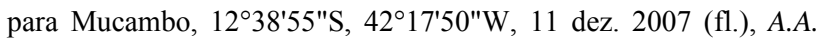
Conceição 2537 (HUEFS); Ilhéus, área do CEPEC, Quadra D, 39॰02'58"W, 1447'20"S, 18. ago. 1981 (fr.), J.L. Hage 1204 (CEPEC); Inhambupe, Litoral Norte, $11^{\circ} 47^{\prime} 04^{\prime \prime S}, 38^{\circ} 21^{\prime} 11^{\prime \prime W}, 14$ fev.1983 (fl., fr.), G.C.P. Pinto 54/83 (ALCB); Ipirá, Paraguaçu, caminho para Torre, $12^{\circ} 09^{\prime} \mathrm{S}, 39^{\circ} 43^{\prime} \mathrm{W}, 21 \mathrm{dez} .2011$ (fl., fr.), M.L. Guedes et al. 19235 (ALCB); Ipupiara, $2 \mathrm{~km}$ na estrada de Ipupiara para Mussambê, $11^{\circ} 49^{\prime} \mathrm{S}, 42^{\circ} 36^{\prime} \mathrm{W}, 26$ jan. 2001 (fr.), E. Saar et al. 40 (ALCB, HUEFS); Itaeté, 12 599'11"S, 40 58'21"W, 13 nov. 2014 (fl.), M.L. Guedes 23075 (ALCB); Itagibá, Litoral Sul, Mata do Laterítico $14^{\circ} 10^{\prime} 35^{\prime \prime} \mathrm{S}, 39^{\circ} 43^{\prime} 55^{\prime \prime} \mathrm{W}, 22$ mar. 2008 (fr.), C.H.A. Ramos et al. 124 (ALCB); Itaju da Colônia, 1508'33"S, $39^{\circ} 43^{\prime} 28^{\prime \prime W}$, s.d. (fr.), T.S. Santos et al. 418 (CEPEC, MBM); Itamaraju, $17^{\circ} 02^{\prime} 22^{\prime \prime} \mathrm{S}, 39^{\circ} 31^{\prime} 52^{\prime \prime} \mathrm{W}$, s.d. (fr.), R. Callejas et al. 1626 (CEPEC); Itabepi, $15^{\circ} 57^{\prime} 03^{\prime \prime} \mathrm{S}, 39^{\circ} 32^{\prime} 02^{\prime \prime} \mathrm{W}, 10$ nov. 1967 (fl.), R.S. Pinheiro et al. 408 (CEPEC, HUEFS); Itatim, 12 $42^{\prime} 43^{\prime \prime S}$, 3941'53"W, 15 dez. 2012 (fl.), E. Melo 11890 (HUEFS); Itiúba, $10^{\circ} 41^{\prime} 30^{\prime \prime S}, 39^{\circ} 51^{\prime} 12^{\prime \prime W}, 19$ fev. 1974 (fr.), R.M. Harley et al. 16213 (CEPEC); Ituaçu, Serra Geral, Morro da Mangabeira

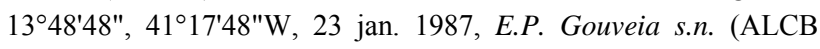
21212); Jacobina, $10 \mathrm{~km}$ na estrada de Jacobina para Morro do Chapéu, $11^{\circ} 10^{\prime} 50^{\prime \prime} \mathrm{S}, 40^{\circ} 31^{\prime} 06^{\prime \prime} \mathrm{W}, 14$ mar. 1990 (fl., fr.), A.M. Carvalho et al. 2791 (HUEFS, MBM); Jaguaquara, 1331'50"S, 39 58'15"W, 26 out. 2012, E. Melo 11606 (HUEFS); Jaguarari, estrada para Grotas, $10^{\circ} 07^{\prime} 59^{\prime \prime} \mathrm{S}, 40^{\circ} 13^{\prime} 00^{\prime \prime} \mathrm{W}, 24$ jun. 2005, A. Rapini 1207 (HUEFS); Jequié, Serra do Castanhão, 135' 22" S, 40¹1'27"W, 25 jul. 2003 (fr.), W.W. Thomas et al. 13543 (HUESB); Jeremoabo, estrada entre Jeremoabo e Canudos, $10^{\circ} 04^{\prime} 07^{\prime \prime S}, 38^{\circ} 28^{\prime} 21^{\prime \prime W}, 27$ jun. 2007 (fr.), R.M. Santos 1666 (HUEFS); Jitaúna, saída de Jequié, $14^{\circ} 01^{\prime} 08^{\prime \prime} \mathrm{S}, 39^{\circ} 53^{\prime} 20^{\prime \prime} \mathrm{W}$, s.d. (fl.), S.R.P. Belém 3386 (CEPEC, NY); Juazeiro, Rodeadouro, $09^{\circ} 41^{\prime} \mathrm{S}, 40^{\circ} 30^{\prime} \mathrm{W}, 20$ jun 2015 (fr.), M.L. Guedes et al. 23854

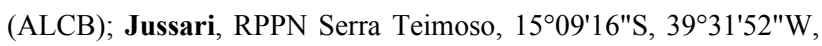
10 dez. 2004 (fl.), A.M. Amorim 4475 (CEPEC, NY); Lajedinho, Mocozeira, 1306'09"S, 4059'58"W, 26 dez. 2014 (fr.), G.E.L. Macedo et al. 2379 (HUESB); Lençóis, assentamento Rio Bonito, ponto R4, 1306'09"S, 4059'58"W, 3 jun. 2001 (fr.), M.L. Guedes et al. 8926 (ALCB, CEPEC); Licínio de Almeida, Serra Geral, 
Lagoa da Vereda, 14³4'11"S, 42²7' 59"W, 11 dez. 2009 (fr.), F.S. Gomes et al. 350 (ALCB, HUEFS); Macajuba, ca. $8 \mathrm{~km} \mathrm{~N}$ de Macajuba na estrada para Baixa Grande, $12^{\circ} 05^{\prime} 26^{\prime \prime S}, 40^{\circ} 18^{\prime} 17^{\prime \prime} \mathrm{W}, 2$ set. 2004 (fr.), L.P. Queiroz 9420 (HUEFS); Maracás, entrada da Boca do Mato, 13²1'54"S, 40²7'10"W, 19 dez. 2004 (fr.), M.M Silva-Castro et al. 927 (HUESB); Miguel Calmon, Piemonte da Diamantina, Entorno do Parque Sete Passagens, Ponto 220, 11'21'22"S, 40³3'11"W, 22 dez. 2006 (fr.), M.L. Guedes et al. 13110 (ALCB); Milagres, Recôncavo Sul, fazenda Bom Jesus, 1252'12"S, 3951'32"W, 7 dez. 1969 (fr.), A.L. Costa s.n. (ALCB 2425); Monte Santo, subida para igreja ao lado da escada, $10^{\circ} 26^{\prime} 16^{\prime \prime S}, 39^{\circ} 19^{\prime} 58^{\prime \prime W}, 27$ fev. 2000 (fl., fr.), A.M. Giulietti \& R.M. Harley 1843 (HUEFS, IAC); Morpará, $11^{\circ} 42^{\prime} \mathrm{S}, 43^{\circ} 13^{\prime} \mathrm{W}, 17$ dez. 2007 (fr.), A.A. Conceição 2725 (HUEFS); Morro do Chapéu, Piemonte da Diamantina, Ventura, $11^{\circ} 33^{\prime} \mathrm{S}, 41^{\circ} 09^{\prime} \mathrm{W}, 4$ abr. 2004 (fr.), M.L. Guedes, 11002 (ALCB, CEPEC); Mundo Novo,

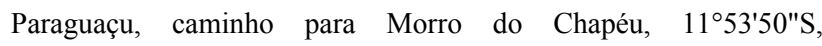
40²9'30"W, 8 dez. 2006 (fr.), M.L Guedes et al. 12900 (ALCB); Nova Ibiá, fazenda Dois Irmãos $13^{\circ} 44^{\prime} 06 " \mathrm{~S}, 39^{\circ} 33^{\prime} 58^{\prime \prime} \mathrm{W}, 12$ ago. 2014 (fr.), R.S. Souza et al. 511 (HUESB); Palmeiras, estrada Palmeira-Iraquara, entrada à direita, depois da gruta da Pratinha, $12^{\circ} 22^{\prime} \mathrm{S}, 41^{\circ} 31^{\prime} \mathrm{W}, 19$ jan. 2008 (fr.), S.F. Conceição et al. 551 (ALCB, HUEFS); Paramirim, caminho de Caturama para Mateus, 13¹7'50"S, 42¹4'44"W, 28 abr. 2007 (fr.), A.A. Conceição 2079 (HUEFS); Pindobaçu, Estrada do Brejo, 1044'30"S, 40²1'39"W, 6 dez. 2003 (fr.), A.M. Miranda 4369 (HUEFS); Pintadas, $11^{\circ} 48^{\prime} 45^{\prime \prime S}, 39^{\circ} 54^{\prime} 31^{\prime \prime W}, 8$ maio 2014 (fr.), L.G. Souza 11 (HURB); Porto Seguro, Parque Nacional Monte Pascoal, $15^{\circ} 15^{\prime} 53$ "S, 40³4'29"W, W.W. Thomas 11323 (CEPEC); Riacho de Santana, Bom Despacho, $10 \mathrm{~km}$ da cidade, 1336' $33^{\circ} \mathrm{S}, 42^{\circ} 56^{\prime} 20^{\prime \prime} \mathrm{W}, 14$ mar. 2002 (fl., fr.), N. Roque et al. 651 (HUEFS, IAC); Ribeira do Pombal, 1050'04"S, 38 32'09"W, 2 fev. 2013 (fr.), G. Costa 1758 (ALCB, HURB); Rio de Contas, Povoado de Baixa Funda, próximo de Arapiranga, 6,4 km NE da cidade de Rio de Contas, em

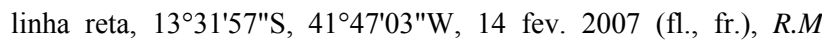
Harley et al. 55565 (HUEFS); Ruy Barbosa, Paraguaçu, margem do rio Água Branca, 1204' 21"S, 40³3'38"W, 19 maio 2001 (fr.), D.L. Santana et al. 538 (ALCB, CEPEC); Salvador, Parque Zoobotânico Getúlio Vargas, $12^{\circ} 58^{\prime} \mathrm{S}, 38^{\circ} 30^{\prime} \mathrm{W}, 6$ ago. 2012 (fr.), PROUFBA 151 (ALCB); São Desidério, BR-135, 12²2'37"S, 445ㅇ'08"W, 2 jul. 2007 (fr.), R.M. Santos 1705 (HUEFS); São Francisco do Conde, 12³7'39"S, 38 40'48"W, 22 fev. 1992 (fr.), F.P. Bandeira s.n. (ALCB 21148a); Saúde, Paulista, Cachoeira do Rio das Pedras, $11^{\circ} 00^{\prime} 24^{\prime \prime S}, 40^{\circ} 26^{\prime} 48^{\prime \prime} \mathrm{W}, 12$ ago 1999 (fr.), E.B Miranda 121 (HUEFS); Senhor do Bonfim, Morro da Antena, 10²7'41"S, 40¹1'22"W, 13 maio 1999 (fl., fr.), F. França et al. 2899 (HUEFS, IAC); Sento Sé, 0944'46"S, 41 ${ }^{\circ} 53^{\prime} 06^{\prime \prime W}, 27$ jan. 2010 (fr.), M. Oliveira 4756 (HVASF); Sobradinho, 09²7'20"S, 40 49'24"W, 2 fev. 2010 (fr.), J.A. Siqueira-Filho 2347 (HVASF); Tanquinho, $11^{\circ} 58^{\prime} 43^{\prime \prime S}, 39^{\circ} 06^{\prime} 14^{\prime \prime} \mathrm{W}, 24$ nov. 1991 (fl.), G. Costa 1758 (ALCB, HURB); Umburanas, 1043'58"S, 41 ${ }^{\circ} 19^{\prime} 45^{\prime \prime} \mathrm{W}, 9$ abr. 2012 (fr.), M.L. Guedes 20636 (ALCB); Urandi, Serra Geral, caminho para o Rio Raízes, Ponto 01, 1445'55"S, 42³9'03"W, 4. ago. 2009 (fl.,), M.L. Guedes et al. 15760 (ALCB); Uruçuca,

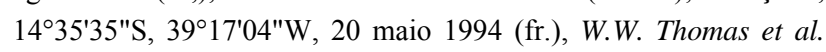
10405 (MBM, NY); Valente, 11²2'59"S, 39²5'59"W, 16 nov. 1986 (fl., fr.), L.P. Queiroz 1117 (HUEFS).

Celtis iguanaea apresenta a maior distribuição dentre as espécies do gênero no Brasil, associada à ampla variação morfológica, incluindo dimensões e pilosidade das folhas e ramos. A maioria dos espécimes pode ser identificada especialmente pelos espinhos recurvados, folhas membranáceas, sem pontuações evidentes (raramente presentes) e com domácias glabras. A espécie mais similar é $C$. brasiliensis, conforme colocado nos comentários daquela espécie.

1.4. Celtis orthacanthos Planch., Ann. Sci. Nat. sér. 3, 10: 309. 1848.

Figuras $1 \mathrm{~L}-\mathrm{O}$ e 4.

Árvores, 24-30 m alt. (DAP. 46-66 cm). Ramos arroxeados, glabros ou com indumento apenas na base dos espinhos e nós, espinhos 1-2 cm compr., retos a recurvados; estípulas $1-4 \mathrm{~mm}$ compr., esparsamente adpresso-pubérulas. Folhas com pecíolo 2-5 $\mathrm{mm}$ compr., adpresso-pubérulo, glabrescente; lâmina 3-8 $\times$ 1,5-4 cm, cartácea a coriácea, elíptica a oblonga, base geralmente assimétrica, obtusa a arredondada, ápice agudo a acuminado, margens serreadas, crenadas ou denteadas, face adaxial sem pontuações visíveis, glabra ou com raros tricomas, adpresso-pubérula nas nervuras principais, face abaxial adpresso-pubérula ou estrigosa sobre as nervuras principais, nervuras 3-5, sem domácias ou domácias recobertas pelo mesmo indumento da lâmina. Drupas $8-15 \times 6-8 \mathrm{~mm}$, glabras.

Celtis orthacanthos é endêmica do Brasil, ocorrendo apenas nos estados da Bahia, Minas Gerais e Rio de Janeiro (Berg \& Dahlberg 2001; BFG 2015; Machado \& Silva 2019). Foi registrada nos domínios da Floresta Atlântica e Cerrado, onde habita florestas ombrófilas densas e florestas ciliares, geralmente em vegetações de baixada e submontanas (BFG 2015). F8 e G8/9. Foi coletada com flores e frutos em junho.

Material examinado - Ilhéus, Quadra do CEPEC, Parque Zoobotânico, 1447'20"S, 3902'58"W, s.d. (fl.), J.L. Hage 2064 (CEPEC); Ituberá, Litoral Sul, mata ciliar da Pancada Grande,

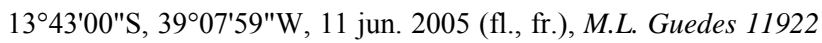
(ALCB, NY).

Material adicional examinado - BRASIL. MINAS GERAIS: Caratinga, Estação Biológica de Caratinga, $19^{\circ} 40^{\prime} \mathrm{S}, 41^{\circ} 50^{\prime} \mathrm{W}, 25$ mar. 1984 (fr.), K.B. Strier 613 (NY); ib., 27 mar. 1984 (fr.), K.B. Strier 836 (NY).

Celtis orthacanthos é a única espécie de $C$. subg. Mertensia no Brasil que chega a $30 \mathrm{~m}$ de altura. Também se distingue pelos ramos arroxeados com lenticelas claras e espinhos arroxeados. $\mathrm{Na}$ Bahia, as duas coletas examinadas são da Mata Atlântica, Litoral Sul.

\section{Trema Lour.}

Árvores ou arbustos eretos. Ramos retos a recurvados, inermes. Folhas alternas; lâmina oval a lanceolada, cartácea, ápice acuminado, base assimétrica, subcordada, margens recortadas desde a base, serreadas, serrilhadas ou denteadas, da base ao 
ápice, venação actinódroma, nervuras 3, sem pontuações evidentes; domácias ausentes. Inflorescências com brácteas inconspícuas, caducas; flores estaminadas em cimeiras e as pistiladas isoladas, ou aos pares, entre as estaminadas. Flores estaminadas pediceladas; receptáculo piloso; sépalas 5 , ovais, pilosas, margens ciliadas; estames 5, filetes curvos no botão, eretos na flor aberta, anteras introrsas, dorsifixas. Flores pistiladas pediceladas, receptáculo piloso; sépalas 5, ovais, pilosas, margens ciliadas; estaminódios 5, decíduos; ovário séssil, 1-locular, estigmas inteiros. Frutos drupas, pouco carnosos, arredondados, glabros, alaranjados a vermelhos na maturidade; sementes marrons a negras.

Trema possui distribuição pantropical e inclui cerca de 20 espécies, seis das quais são citadas para as Américas (Grudzinskaya 1993). A única espécie tradicionalmente registrada para o Brasil é $T$. micrantha (L.) Blume (Carauta 1968, 1974; BFG 2015; Machado \& Silva 2019). Porém, Miquel (1853) já havia sinalizado a ocorrência de duas espécies no país, sob o gênero Sponia Decne [S. micrantha (L.) Decne. e S. mollis Decne.], diferenciadas principalmente pelo indumento denso e esbranquiçado nos ramos e folhas de S. mollis.

Machado et al. (2004) e Machado (2005) discutiram a possibilidade de Trema mollis (Willd.) Blume ser reconhecida como distinta de T. micrantha. No presente trabalho, essas duas espécies são consideradas distintas.

\section{Chave para as espécies}

1. Ramos esverdeados, tricomas geralmente esparsos; estípulas acuminadas, 2-3 mm compr.; lâmina foliar com margens serreadas, face abaxial áspera a pubescente, nervação terciária impressa; brácteas e bractéolas acuminadas, 1-2 mm compr.; pedicelos e flores glabrescentes; estigma caduco no fruto

\subsection{T. micranth}

1'. Ramos brancos ou acinzentados, tricomas densos; estípulas longo-acuminadas, 4-5 $\mathrm{mm}$ compr.; lâmina foliar com margens serrilhadas, face abaxial densamente alvo-pilosa, nervação terciária proeminente; brácteas e bractéolas longoacuminadas, 2-4 $\mathrm{mm}$ compr.; pedicelos e flores pubescente-hirsutos; estigma persistente no fruto ....

2.2. T. mollis

2.1. Trema micrantha (L.) Blume, Ann. Mus. Bot. Lugd. Bat. 2: 58. 1856.

Figuras 2C-E, 6A-B e 7.

Árvores a arbustos $2-10 \mathrm{~m}$ alt. Ramos esverdeados, tricomas geralmente esparsos; estípulas 2-3 mm compr., acuminadas. Folhas com pecíolo 5$18 \mathrm{~mm}$ compr., glabro; lâmina $6,5-9,5 \times 3,0-4,2 \mathrm{~cm}$, membranácea a cartácea, oval a lanceoladas, margens serreadas, face adaxial áspera, tricomas curtos esparsos, face abaxial áspera, pubescente, tricomas curtos, 3 ou 4 pares de nervuras secundárias, nervação terciária impressa. Inflorescências com brácteas e bractéolas acuminadas, 1-2 mm compr.; pedicelos e flores glabrescentes. Drupas 3-4 × ca. $3 \mathrm{~mm}$, estigma caduco.

Espécie com ampla distribuição nas Américas (Carauta 1974). No Brasil, ocorre em todas as regiões e domínios fitogeográficos (BFG 2015; Machado \& Silva 2019). Na Bahia, ocorre em floresta ciliar ou galeria, floresta estacional semidecidual e floresta ombrófila: B6, C1, C6, C7, C8, D6, D7, E2/3, E6, E7, E8, E9, F6, F7, F8, G5, G7, G8, H8, I8/9 e J8. Floresce durante $\mathrm{o}$ ano todo.

Material selecionado - Abaíra, 13¹4'S, 41³9'W, 2 jan. 1993 (fl.), W. Ganev 1765 (HUEFS, NY); Alagoinhas, Campus II/UNEB, $12^{\circ} 08^{\prime} \mathrm{S}, 38^{\circ} 25^{\prime} \mathrm{W}, 5$ nov. 2002 (fl.), M.R. Fonseca s.n. (HUEFS 88584); Almadina, $5,3 \mathrm{~km}$ de Almadina na rodovia para Ibitupã, depois à esquerda, 7,9 km na rodovia para Serra dos Sete Paus, $14^{\circ} 42^{\prime} \mathrm{S}$, 39³8'W, s.d. (fl.), W.W. Thomas 11471 (CEPEC); Amargosa, Serra do Timbó, área de estudos do Projeto Timbó, Centro Sapucaia, $13^{\circ} 01^{\prime} \mathrm{S}, 39^{\circ} 36^{\prime} \mathrm{W}, 27$ jan. 2007 (fl.), D. Cardoso 1637 (HUEFS); Andaraí, 12²48'S, 41¹9'W, 9 out. 1987 (fl.), L.P. Queiroz 1830 (HUEFS, NY); Arataca, Serra do Peito-de-Moça, estrada que liga Arataca a Una, ramal cerca de 22,4 km de Arataca com entrada no assentamento Santo Antônio, RPPN Caminho das Pedras, $15^{\circ} 15^{\prime} \mathrm{S}, 39^{\circ} 24^{\prime} \mathrm{W}, 19$ jan. 2007 (fl.), A.M. Amorim 6664 (CEPEC, NY); Barra do Choça, cerca de $12 \mathrm{~km}$ a SE da cidade, na rodovia para Itapetinga, $14^{\circ} 52^{\prime} \mathrm{S}, 40^{\circ} 34^{\prime} \mathrm{W}$, s.d (st.), R.M. Harley 20191 (CEPEC); Cachoeira, 12³7'06"S，38 ${ }^{\circ} 57^{\prime} 21^{\prime \prime} \mathrm{W}, 10$ nov. 20018 (fl.), F.S. Fadigas HURB 773 (HURB); Caetité, 140. $4^{\prime} 10^{\prime \prime S}$, 42²8'30"W, 26 abr. 2009 (fl.), J.L. Paixão 1599 (UESC); Cairu, Baixo Sul, Morro de São Paulo, 13⒉'S, 3902'W, 28 out. 1996 (fr.), M.L. Guedes \& M. Accioly 4064 (ALCB); Camacan, RPPN Serra Bonita, 9,7 km de Camacan na estrada para Jacareci, daí $6 \mathrm{~km}$ SW na estrada para a RPPN e torre da Embratel, $15^{\circ} 25^{\prime} \mathrm{S}, 39^{\circ} 29^{\prime} \mathrm{W}$, 9 dez. 2006 (fl., fr.), R.A.X. Borges 304 (HUEFS); Camamu,

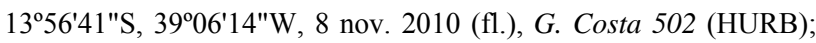
Canavieiras, 1540'30"S, 38 $566^{\prime} 50^{\prime \prime} \mathrm{W}, 13$ jun. 2003 (fr.), G. Hatschbach 75290 (MBM); Contendas do Sincorá, cerca de $2 \mathrm{~km}$ em direção a Pé de Serra, $13^{\circ} 45^{\prime} \mathrm{S}, 41^{\circ} 02^{\prime} \mathrm{W}, 28$ fev. 2000 (st.), M.M. Silva-Castro 346 (HUEFS); Cravolândia, assentamento Palestina, $13^{\circ} 21^{\prime} \mathrm{S}, 39^{\circ} 48^{\prime} \mathrm{W}, 14$ ago. 2001 (fl.), D.M. Loureiro et al. 433 (ALCB); Cruz das Almas, Mata da Cazuzinha, $12^{\circ} 40^{\prime} \mathrm{S}, 39^{\circ} 06^{\prime} \mathrm{W}, 4$ nov. 2011 (fl. fr.), G. Costa \& S.F. Conceição 576 (ALCB); Elísio Medrado, Recôncavo Sul, Serra da Jiboia, Reserva Jequitibá, $12^{\circ} 56$ 'S, 39³1'W, 8 fev. 2011 (fl. fr.), M.L. Guedes et al. 17933 (ALCB); Feira de Santana, Paraguaçu, fazenda Boa Vista, Serra de São José, 12¹6'S, 38 58 'W, 10 maio 1984 (fl.), L.R. Noblick 3195 (HUEFS, ALCB, CEPEC); Ibicoara, fazenda Ribeirão da Serra, margem do rio Sincorá, ca. $2 \mathrm{~km}$ a nordeste da sede, $13^{\circ} 24^{\prime} \mathrm{S}$, 41ํ1' W, 10 mar. 1999 (fr.), L.A. Passos Júnior \& A.L.R. Nogueira 245 (ALCB, CEPEC); Igrapiúna, Reserva Ecológica das Plantações Michellin da Bahia, 13ํำ'S, 390 $08^{\prime}$ W, 1 dez. 2010 (fr.), J.L. Paixão 1855 (HUEFS); Ilhéus, Litoral Sul, Parque Municipal da Boa Esperança, caminho até a represa, $14^{\circ} 47^{\prime} \mathrm{S}, 39^{\circ} 02^{\prime} \mathrm{W}, 8$ maio 2001 (st.), L.C.B. Costa et al. 179 (ALCB, HUEFS); Itaberaba, Serra do Orobó, fazenda Gameleira, $12^{\circ} 31^{\prime} \mathrm{S}, 40^{\circ} 18^{\prime} \mathrm{W}, 18$ jan. 2006

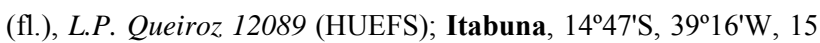
dez. 1966 (fl.), L.E. Mello Filho 2403 (R); Itacaré, 14³6'19"S, 38 $59^{\prime} 48^{\prime \prime W}$, s.d. (fr.), M.F. Fernandes 358 (HUEFS); Itaeté, 

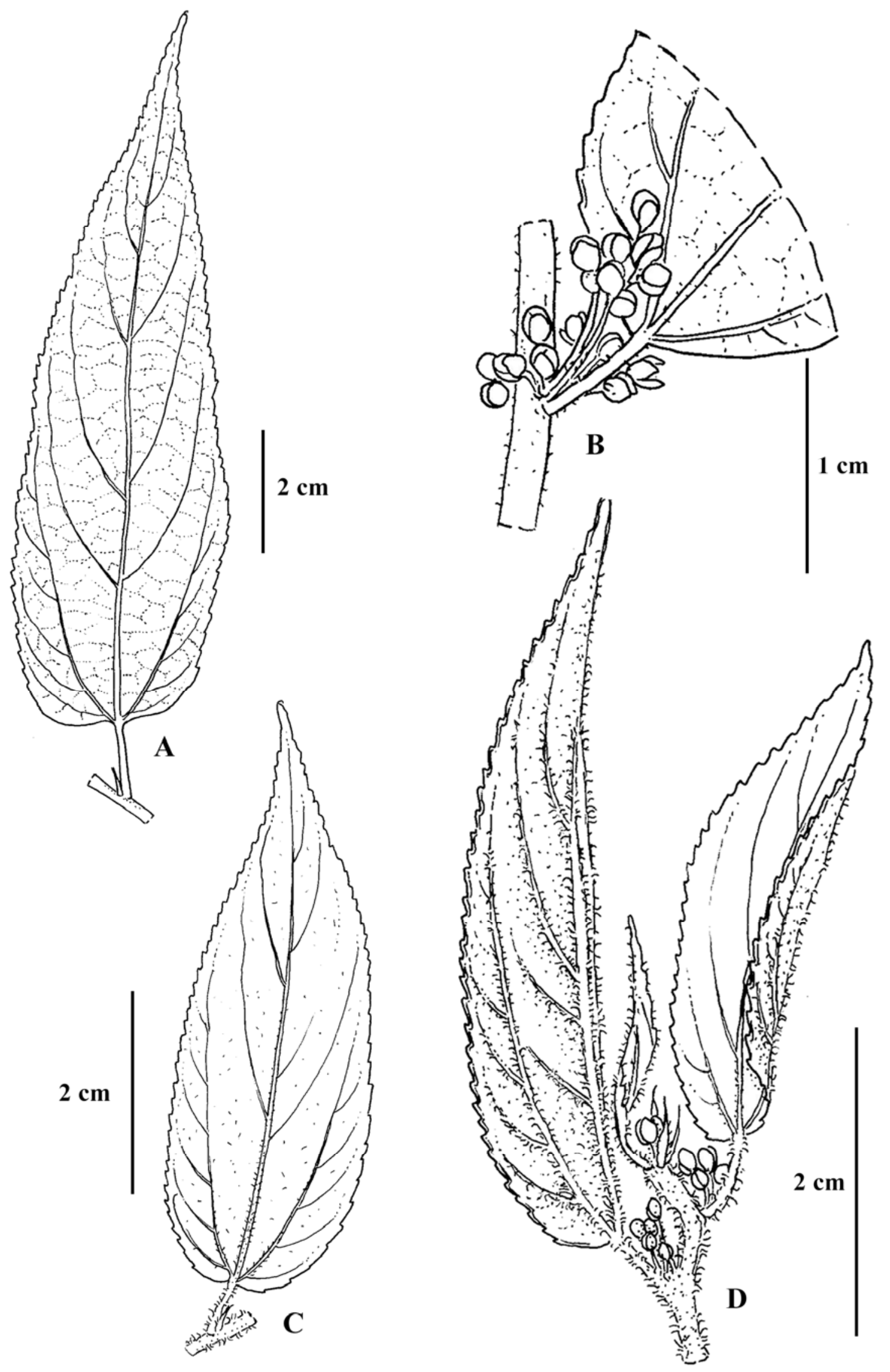

Figura 6. A, B. Trema micrantha: A- face adaxial da folha, com detalhe do ramo e estípula; B- inflorescência axilar (Borges 304). C, D. Trema mollis: C- face adaxial da folha, com estípula; D- detalhe do ramo mostrando a face abaxial da folha e flores (Jardim 3580). 


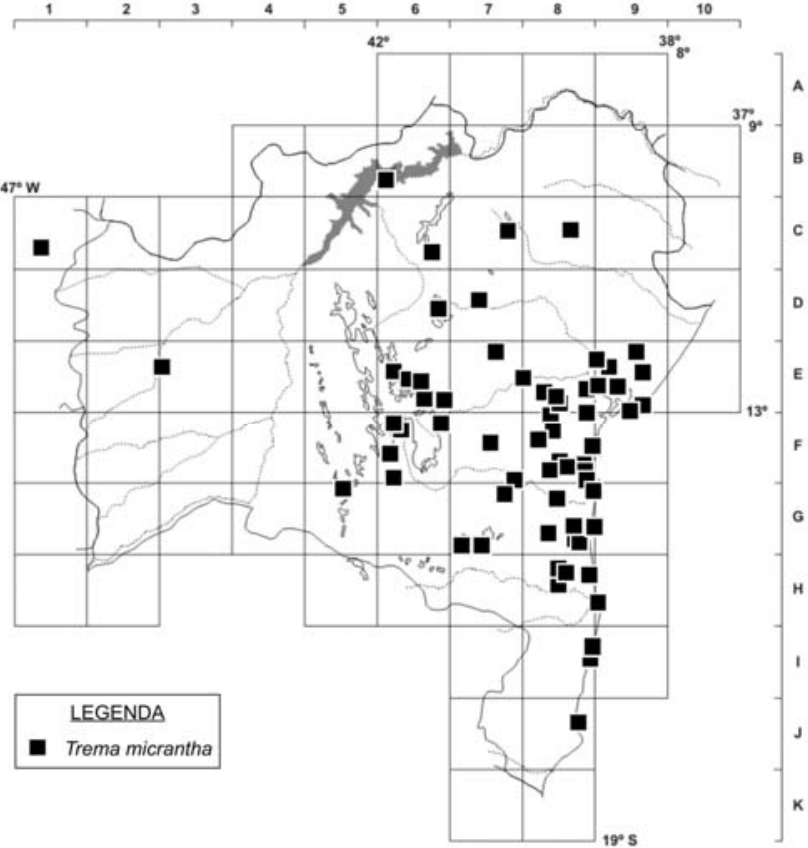

Figura 7. Distribuição geográfica de Trema micrantha no estado da Bahia.

Paraguaçu, assentamento Baixão, margem esquerda do rio Una, área de reserva, 12 ${ }^{\circ} 59^{\prime} \mathrm{S}, 40^{\circ} 58^{\prime} \mathrm{W}, 13$ abr. 2001 (st.), L. Alves et al. 50 (ALCB, CEPEC); Itatim, Morro do Agenor, $12^{\circ} 42^{\prime} \mathrm{S}, 39^{\circ} 41^{\prime} \mathrm{W}, 29$ jun. 1996 (fl.), E. Melo 1637 (HUEFS); Itiúba, saída para Coité, morro à direita da ferrovia, 10² $41^{\prime} \mathrm{S}, 39^{\circ} 51^{\prime} \mathrm{W}, 10$ maio 2002 (fr.), J.G.A. Nascimento 82 (HUEFS, IAC); Ituberá, Fazendas Reunidas Vale do Juliana, na estrada depois do mirante, $13^{\circ} 43^{\prime} \mathrm{S}, 39^{\circ} 08^{\prime} \mathrm{W}, 7$ fev. 2004 (st.), J.G. Carvalho-Sobrinho 195 (HUEFS); Jacobina, Piemonte da Diamantina, Mata dos Bandeirantes, $11^{\circ} 10^{\prime} \mathrm{S}, 40^{\circ} 31^{\prime} \mathrm{W}$, 8 abr. 2001 (fl.), N.G. Jesus et al. 1351 (ALCB, HUEFS, UESC); Jacuípe, Estrada do Coco, próximo de Jacuípe, $12^{\circ} 21^{\prime} \mathrm{S}, 38^{\circ} 48^{\prime} \mathrm{W}$, 11 fev. 1980 (fl.), A.P. Araújo 191 (ALCB); Jequié, estrada para Pé de Serra, 1351'S, 4005'W, s.d. (fl.), M. Sobral 5915 (CEPEC, MBM); Jiquiriçá, fazenda Araçá, 13º's, 39³4'W, 3 set. 2014 (fr.), R.S. Souza et al. 616 (HUESB); Jussari, rodovia para Palmira, entrada ca. 7,5 km percorrendo mais $1,7 \mathrm{~km}$ até a sede da fazenda Teimoso, RPPN Serra do Teimoso, $15^{\circ} 11^{\prime} \mathrm{S}, 39^{\circ} 29^{\prime} \mathrm{W}$, s.d. (fl.), J.G. Jardim 1582 (CEPEC, NY); Lauro de Freitas, 12 ${ }^{\circ} 53^{\prime} \mathrm{S}, 38^{\circ} 19^{\prime} \mathrm{W}, 7$ mar. 1989 (fl.), R. Soeiro 50/89 (UESC); Lençóis, 15 km NW Lençóis, rodovia entre Seabra e Itaberaba. Morro do Pai Inácio, $12^{\circ} 33^{\prime} \mathrm{S}, 4^{\circ} 23^{\prime} \mathrm{W}$, s.d. (fl.), R.M. Harley 22640 (CEPEC); Livramento de Nossa Senhora, estrada entre Rio de Contas e Livramento de Nossa Senhora, 1208'S, 40² $1^{\prime} \mathrm{W}, 31$ jan. 2005 (fl. fr.), J. Paula-Souza et al. 5209 (ESA); Macajuba, ca. $8 \mathrm{~km} \mathrm{~N} \mathrm{de}$ Macajuba na estrada para Baixa Grande, $14^{\circ} 08^{\prime} \mathrm{S}, 40^{\circ} 14^{\prime} \mathrm{W}, 2$ set. 2004 (fl.), L.P. Queiroz 9416 (HUEFS); Manoel Vitorino, Morro da Cruz, $13^{\circ} 26^{\prime} \mathrm{S}, 40^{\circ} 25^{\prime} \mathrm{W}, 16$ maio 2002 (fl.), M.M. Silva-Castro 555 (HUEFS); Maracás, Sudoeste, $7 \mathrm{~km}$ ao SW de Maracás, na estrada para Contendas do Sincorá, 28²6'S, 52¹2'W, 23 mar. 1988 (fl.), S. Ginzbarg et al. 848 (ALCB, CEPEC, NY); Maraú, 11 km de Maraú na rodovia para Campinho, $14^{\circ} 06^{\prime} \mathrm{S}, 39^{\circ} 00^{\prime} \mathrm{W}$, s.d (fl.), R.M. Harley 22215 (CEPEC); Miguel Calmon, 11²5'S, 40³5'W, 6 abr. 2001 (fl.), T. Ribeiro 148 (UESC, CEPEC); Monte Santo, Nordeste, $10^{\circ} 26^{\prime}$ S, 39 $19^{\circ} \mathrm{W}, 11$ jan. 2006 (fl.), M.L. Guedes et al. 12096 (ALCB, CEPEC); Morro do Chapéu, Buraco da Duda, $11^{\circ} 33^{\prime} \mathrm{S}, 41^{\circ} 09^{\prime} \mathrm{W}, 7$ nov. 2008 (fl.), E. Melo 6033 (HUEFS); Muniz Ferreira, 1300'10"S, 3906'36"W, 11 abr. 2018 (fl.), G.V. Fonseca 174 (HURB); Nova Ibiá, Fazenda da Cabeceira, 134' $\mathrm{S}, 39^{\circ} 37^{\prime} \mathrm{W}$, 6 jun. 2013 (fr.), R.S. Souza et al. 260 (HUESB, NY); Nova Redenção, Peruca, margem do rio Paraguaçu, $12^{\circ} 49^{\prime} \mathrm{S}, 4^{\circ} 04^{\prime} \mathrm{W}, 2$ mar. 2003, L.R. Senna 149 (HUEFS); Palmeiras, em frente a casa do caseiro de R. Linsker, $12^{\circ} 31^{\prime} \mathrm{S}, 4^{\circ} 33^{\prime} \mathrm{W}, 11$ mar. 2004 (fl. fr.), A.A. Conceição 1122 (HUEFS); Piatã, estrada para Catolés, 1309'S, 4146'W, 24 mar. 2005 (fr.), M.L. Guedes et al. 11514 (ALCB); Piraí do Norte, BA-544, às margens da rodovia, sentido para Gandu, 134' S, 39² $22^{\prime} \mathrm{W}, 6$ maio 2014 (fr.), R.S. Souza et al. 500 (HUESB); Pojuca, Litoral Norte, Catu, Campo de Água Grande, 12²5'S, 38'19'W, 1 ago. 1990 (fl.), M.C. Ferreira 283 (ALCB); Porto Seguro, Parque Nacional do Monte Pascoal, 16²' 'S, 3903'W, 13 jan. 1977 (fr.), R.M. Harley 17913 (CEPEC); Prado, Extremo Sul, 17²0'S, 39²13'W, 28 jul. 1984 (fr.), A. Lima \& M.M. Santos 128 (ALCB, CEPEC, HUEFS, NY); Rio de Contas, início da estrada para Capela de Bom Jesus, $13^{\circ} 34^{\prime} \mathrm{S}, 41^{\circ} 48^{\prime} \mathrm{W}, 30$ mar. 2002 (fl.), A.M. Giulietti 2074 (HUEFS); Salvador, arredores da Faculdade de Engenharia, 1258'S, 38³0'W, 13 set. 1980 (fr.), L.P. Queiroz 41 (ALCB); Santa Cruz Cabrália, Extremo Sul, área de plantação de eucalipto da Veracel Celulose, Sapucaieira, parcela 03, 16 ${ }^{\circ} 16^{\prime} \mathrm{S}, 39^{\circ} 01^{\prime} \mathrm{W}, 7$ nov. 2000 (fl.), L.M. Pacheco et al. 134 (ALCB); Santa Terezinha, Serra da Jiboia, à margem da estrada da Serra da Pioneira, $12^{\circ} 46^{\prime} \mathrm{S}, 39^{\circ} 31^{\prime} \mathrm{W}, 14$ fev. 2001, A.A. RibeiroFilho 181 (HUEFS, MBM); São Desidério, BR-135, 12²1'S, 445' 'W, 2 jul. 2007 (fl.fr.), R.M. Santos 1728 (HUEFS); São Francisco do Conde, fazenda Engenho Madruga, $12^{\circ} 37^{\prime} \mathrm{S}, 38^{\circ} 40^{\prime} \mathrm{W}$, 22 fev. 1992 (fr.), F.P. Bandeira s.n. (ALCB 24147); Seabra, BR242, entre Seabra e Lençóis, $12^{\circ} 25^{\prime} \mathrm{S}, 41^{\circ} 46^{\prime} \mathrm{W}, 18$ maio 2002 (fl.), E.R. Souza 321 (HUEFS); Senhor do Bonfim, Morro da Antena, ca. $11 \mathrm{~km} \mathrm{~S}$ de Senhor do Bonfim, 10²7'S, 40¹1'W, 13 maio 1999 (fl.), F. França 2901 (HUEFS, IAC); Sento Sé, afloramento rochoso Olho d'Água, PNBO, 0944'S, 4153'W, 1 fev. 2010 (fr.), J.A. Siqueira Filho 2341 (HVASF); Ubatã, rodovia para Ibirapitanga, $14^{\circ} 12^{\prime} \mathrm{S}, 39^{\circ} 31^{\prime} \mathrm{W}$, s.d. (fl.), R.S. Pinheiro 83 (CEPEC); Una, fazenda com plantação de seringueira, $15^{\circ} 17^{\prime} \mathrm{S}, 39^{\circ} 04^{\prime} \mathrm{W}, 28$ dez. 2005 (fr.), S.F. Conceição 442 (HUEFS); Uruçuca, 14³5'S, 39¹7'W, 17 nov. 1997 (fl.), R.H.R. Sambuichi 44 (UESC); Vitória

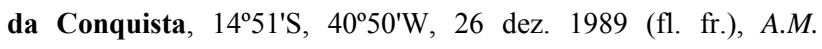
Carvalho 2611 (HUEFS, CEPEC); Wenceslau Guimarães, 1341'13"S, 39²8'46"W, 16 jan. 1991 (fl.), E. Melo 505 (UB).

Trema micrantha possui distribuição neotropical e apresenta ampla variação morfológica (Grudzinskaya 1993), o que também foi observado nos materiais da Bahia, especialmente em relação as dimensões das folhas e comprimento das inflorescências. Atualmente, a espécie tem mais de 40 sinônimos reconhecidos (Machado 2005).

2.2. Trema mollis (Willd.) Blume, Ann. Mus. Bot. Lugd. Bat. 2: 58. 1856.

Figuras 6C-D e 8.

Arbustos, raramente árvores, 2-5 $\mathrm{m}$ alt. Ramos pubescentes, brancos ou acinzentados, indumento denso; estípulas 4-5 mm compr., longo-acuminadas. Folhas com pecíolo 7-10 mm compr., piloso; lâmina 9-10 × 2,5-3,6 cm, membranácea a cartácea, oval a oblonga, margens serrilhadas, face adaxial áspera, 


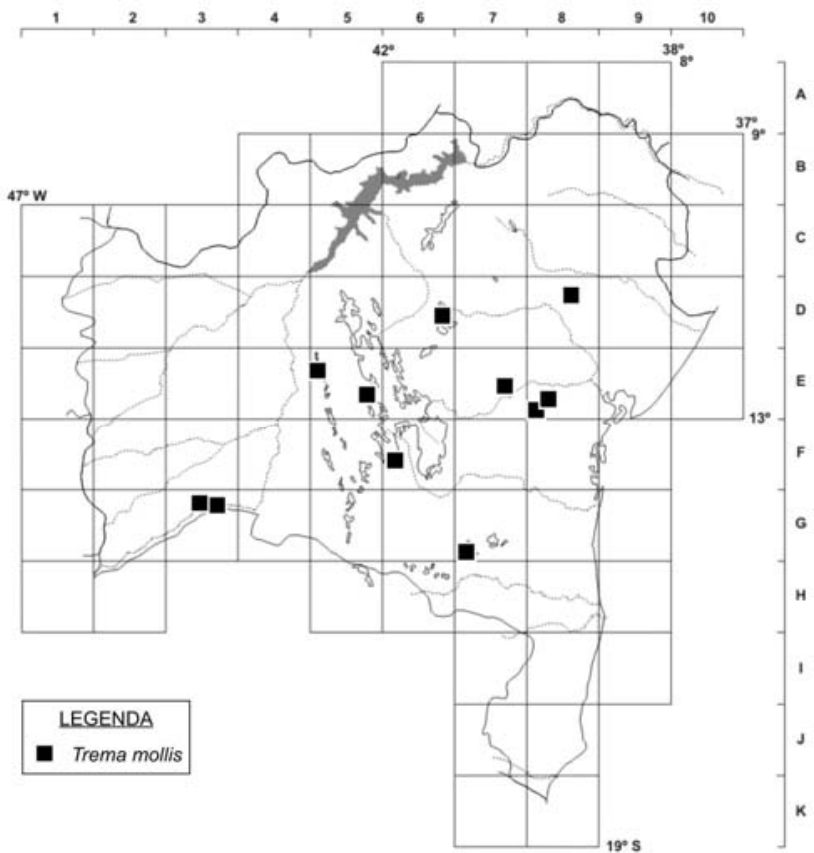

Figura 8. Distribuição geográfica de Trema mollis no estado da Bahia.

tricomas esparsos e curtos, geralmente rugosa, face abaxial com indumento alvo-piloso denso, tricomas alongados, com 4 ou 5 pares de nervuras secundárias, nervação terciária proeminente. Inflorescências com brácteas e bractéolas longo-acuminadas, 2-4 $\mathrm{mm}$ compr.; pedicelos e flores pubescente-hirsutos. Drupas 4-5 mm diâm., estigma persistente.

Trema mollis ocorre em Santo Domingo, Colômbia, Guiana e no Brasil (Miquel 1853), na Amazônia e na Bahia. D6, D8, E5, E7, E8, F6, G3 e G7: Caatinga e Cerrado. Floresce de dezembro a janeiro e de março a abril, tendo sido coletada com frutos em janeiro e março.

Material selecionado - Cocos, fazenda São Domingos, $14^{\circ} 11^{\prime} \mathrm{S}, 4^{\circ} 32^{\prime} \mathrm{W}, 24$ set. 2007 (fl.), M.L. Guedes et al. 13574 (ALCB); Feira da Mata, rodovia para Cocos, $12 \mathrm{~km}$ de Cocos, $14^{\circ} 12^{\prime} \mathrm{S}, 4^{\circ} 16^{\prime} \mathrm{W}, 17$ abr. 2001 (fl.), J.G. Jardim 3580 (ALCB, CEPEC, HUEFS, NY); Ibitiara, estrada lbitiara para Mucambo, $12^{\circ} 39^{\prime} \mathrm{S}, 42^{\circ} 13^{\prime} \mathrm{W}, 11$ out. 2007 (fl.), A.A. Conceição 2541 (HUEFS); Itaberaba, fazenda Itibiraba, base do inselbergue, $12^{\circ} 31$ 'S, 40 $18^{\prime} \mathrm{W}, 19$ mar. 2006 (fl.), E. Melo 4315 (HUEFS); Itatim, Morro do Leão, 12²4'S, 3901'W, 26 out. 1996 (fl.), F. França 1920 (HUEFS); Milagres, Recôncavo Sul, morro Pé de Serra, 1252'S, 3951'W, 15 mar. 1997 (fl. fr.), F. França et al. 2142 (ALCB, HUEFS); Morro do Chapéu, cerca de $2 \mathrm{~km} \mathrm{da}$ comunidade Gruta dos Brejões, $11^{\circ} 33^{\prime} \mathrm{S}, 41^{\circ} 09^{\prime} \mathrm{W}, 5$ maio 2007 (fl.), D. Cardoso 1882 (HUEFS, MBM); Oliveira dos Brejinhos, estrada para Água Quente, $12^{\circ} 19^{\prime} \mathrm{S}, 42^{\circ} 53^{\prime} \mathrm{W}, 18 \mathrm{dez}$. 2007 (fl.), A.A. Conceição 2735 (HUEFS); Rio de Contas, Estrada Real, parte no meio, $13^{\circ} 34^{\prime} \mathrm{S}, 41^{\circ} 48^{\prime} \mathrm{W}, 2$ jan. 2000 (fl. fr.), A.M. Giulietti 1662 (HUEFS, MBM); Santaluz, fazenda Caraconha, Serra da Caraconha, $11^{\circ} 15^{\prime} \mathrm{S}, 39^{\circ} 22^{\prime} \mathrm{W}, 31 \mathrm{dez} .2005$ (fl.), C.T. Lima 35 (HUEFS); Vitória da Conquista, Serra do Peri-Peri, $14^{\circ} 51^{\prime} \mathrm{S}, 40^{\circ} 50^{\prime} \mathrm{W}, 8$ out. 2015 (st.), A.F.P. Machado 1402 (HVC).
A espécie foi reconhecida por Miquel (1853) como Sponia mollis e, posteriormente, incluída na sinonímia de Trema micranta, posição aceita por autores mais recentes (e.g., Carauta 1968, 1974; Grudzinskaya 1993; BFG 2015; Machado \& Silva 2019). Porém, a análise dos materiais provenientes do semiárido baiano, indicou que $T$. mollis pode ser separada de $T$. micrantha tanto por caracteres vegetativos (e.g., indumento dos ramos e folhas, tricomas, forma $\mathrm{e}$ dimensões das estípulas) como por características do fruto, como estigma persistente em T. mollis. O reestabelecimento da espécie é proposto no presente trabalho, conforme previamente sinalizado por Machado et al. (2004) e Machado (2005).

\section{Agradecimentos}

Aos curadores dos herbários ALCB, ASE, CEPEC, HRB, HUEFS, pelo acesso às coleções. Ao $\mathrm{CNPq}$ e à FAPESB, pelo financiamento dos projetos de apoio à Flora da Bahia (FAPESB APR 162/2007 e CNPq processos 562278/2010-9 e 483909/2012-2) e PPBio Semiárido. À Fapesb, pela bolsa de doutorado concedida a AFPM (BOL0563/2014); à CAPES, pela bolsa de doutorado concedida a MFOS, e ao CNPq, pelas bolsas de produtividade em pesquisa concedidas a AMG (PQ Senior) e RPO (PQ1C). À Michella Del Rei, pelas ilustrações, e aos colegas Cecília Azevedo (UESB), Leandro Pederneiras (JBRJ) e Marcelo Vianna F. (UERJ), pelas fotos.

\section{REFERÊNCIAS}

APG IV 2016. An update of the Angiosperm Phylogeny Group classification for the orders and families of flowering plants: APG IV. Botanical Journal of the Linnean Society 181: 1-20.

Berg, C.C. \& Dahlberg, S.V. 2001. A revision of Celtis subg. Mertensia (Ulmaceae). Brittonia 53(1): 66-81.

BFG - The Brazilian Flora Group 2015. Growing knowledge: an overview of seed plant diversity in Brazil. Rodriguésia 66(4): $1085-1113$.

Callaway, J.C. 2004. Hempseed as a nutritional resource: an overview. Euphytica. 140: 65-72.

Carauta, J.P.P. 1968. Catálogo dos gêneros de Ulmaceae no Brasil. Sellowia. 20: 27-29.

Carauta, J.P.P. 1974. Índice das espécies de Ulmaceae do Brasil. Rodriguésia. 27(39): 99-134.

Giannasi, D.E. 1978. Generic relationships in the Ulmaceae based on flavonoid chemistry. Taxon 27: 331-344.

Grudzinskaya, I.A. 1993. Notas sobre el género Trema Lour. (Celtidaceae) del Nuevo Mundo. Boletin del Instituto de Botánica, Universidad de Guadalajara [Bol. IBUG], Epoca 3, 1: 465-470.

Kubitzki, K. 1993. Cannabaceae. In: K. Kubitzki, J.G. Rohwer \& V. Bittrich (eds), The Families and Genera of Vascular Plants. Flowering plants. Dicotyledons Magnoliid, Hamamelid and Caryophyllid families. Vol. 7. Springer-Verlag, Berlin, Heidelberg, p. 204-206. 
Machado, A.F.P. 2005. Trema (Ulmaceae s.l.) no Estado do Rio de Janeiro. Monografia de conclusão de Bacharelado em Ciências Biológicas, Universidade Federal do Rio de Janeiro.

Machado, A.F.P. 2019. Ulmaceae. In: Flora do Brasil 2020 em construção. Jardim Botânico do Rio de Janeiro. Disponível em: $<$ http://www.floradobrasil.jbrj.gov.br/reflora/floradobrasil/FB21 357>. Acesso em: 15 Mai. 2019.

Machado, A.F.P. \& Silva, M.F.O. 2019. Cannabaceae. In: Flora do Brasil 2020 em construção. Jardim Botânico do Rio de Janeiro. Disponível em: <http://www.floradobrasil.jbrj.gov.br/ reflora/floradobrasil/FB21357>. Acesso em: 15 Mai. 2019.

Machado, A.F.P.; Neves, L.J. \& Carauta, J.P.P. 2004. Trema canescens e T. mollis (Ulmaceae), espécies distintas ou sinônimos? Albertoa 19: 141-142.

Martins E.G.A. \& Pirani, J.R. 2009. Flora da Serra do Cipó: Cannabaceae. Boletim de Botânica da Universidade de São Paulo 27: 247-251.

Miquel, F.A.G. 1853. Ulmaceae. In: C.F.P. Martius, A.W. Eichler \& I. Urban (eds), Flora Brasiliensis. Vol. 4, pars 1. Fleisher, Leipzig, p. 170-182, tab. 62-63.

Oomah, B.D.; Busson, M.; Godfrey, D.V. \& Drover J.C.G. 2002. Characteristics of hemp (Cannabis sativa L.) seed oil. Food Chemistry 76: 33-43.

Pederneiras, L.C.; Costa, A.F.; Araújo, D.S.D. \& Carauta, J.P.P. 2011. Ulmaceae, Cannabaceae e Urticaceae das restingas do estado do Rio de Janeiro. Rodriguésia 62(2): 299-313.

Romanczuk, M.C. \& Martinez, M.A.P. 1978. Las espécies del género Celtis en la flora argentina. Darwiniana 21(2-4): 541577.
Sattarian, A. 2006. Contribution to the Biosystematics of Celtis L. (Celtidaceae) with Special Emphasis on the African Species. $\mathrm{PhD}$ thesis. Wageningen University, Wageningen.

Stevens, P.F. 2015. Cannabaceae. In: Angiosperm Phylogeny Website. Version 12, July 2012 [and more or less continuously updated since]. Disponível em: http://www.mobot.org/MOBOT/ research/APweb/; acesso em: 5 jul. 2018.

Sun, M.; Naeem, R.; Su, J.-X.; Cao, Z.; Burleigh, G.; Soltis, P.S.; Soltis, D.E \& Chen, X. 2016. Phylogeny of the Rosidae: a dense taxon sampling analysis. Journal of Systematics and Evolution 54: 363-391.

Todzia, C.A. 1993. Ulmaceae. In: K. Kubitzki, J.G. Rohwer \& V. Bittrich (eds), The Families and Genera of Vascular Plants. Flowering plants. Dicotyledons Magnoliid, Hamamelid and Caryophyllid families. Vol. 7. Springer-Verlag, Berlin, Heidelberg, p. 603-611.

Wiegrefe, S.J.; Systma, K.J. \& Guries, R.P. 1998. The Ulmaceae, one family or two? Evidence from chloroplast DNA restriction site mapping. Plant Systematics and Evolution 210: 249-270.

Yang, M.; van Velzen, R.; Bakker, F.T.; Sattarian, A.; Li, D. \& Yi, T. 2013. Molecular phylogenetics and character evolution of Cannabaceae. Taxon 62(3): 473-485.

Zanoli, P. \& Zavatti, M. 2008. Pharmacognostic and pharmacological profile of Humulus lupulus L. Journal of Ethnopharmacology 116: 383-396.

Zuardi A.W.; Crippa J.A.S.; Hallak J.E.C.; Moreira F.A. \& Guimarães F.S. 2006. Cannabidiol, a Cannabis sativa constituent, as an antipsychotic drug. Brazilian Journal of Medical and Biological Research 39: 421-429.

\section{LISTA DE EXSICATAS}

Almeida, E.D.S. 4, 10 (1.3); Alves, L.J. 50 (2.1), 76 (1.3); Alves, T.N. 54 (1.3); Amorim, A.M. 995, 2182, 2688 (1.1), 4475 (1.3), 6664 (2.1); Aona, L.Y.S. 2100 (1.1); Araújo, A.P. 191 (2.1), 204 (1.1), 568 (2.1); Araújo, J. 16 (2.1); Arbo, M.M. 7345 (1.1); Argolo, A.S. 31 (2.1); Bandeira, F.P. ALCB 24148a (1.3), ALCB 24147 (2.1); Bastos, C.A. 13 (1.3); Bautista, H.P. 931 (1.3), 3045 (1.2), PCD 3715, PCD 3716 (1.2); Belém, R.P. 554 (2.1), 3386 (1.3); Borba, E.L. 2044 (1.2); Borges, R.A.X. 304 (2.1); Brazão, J.E.M. 348 (1.3); Brito, H.S. 231, 253 (2.1); Callejas, R. 1626 (1.3); Cardoso, D. 1637 (2.1), 1881 (1.1), 1882 (2.2), 1932 (1.3); Carvalho, A.N. 14 (2.1); Carvalho, A.M. 1316 (2.1), 1573 (1.1), 1935 (1.2), 2611 (2.1), 2791 (1.3); Carvalho, D.N. 187 (1.1); 244 (1.3); Carvalho, G. 33 (2.1); CarvalhoSobrinho, J.G. 141 (2.1), 176 (1.1), 195 (2.1), 3217 (1.2); Casaes, M. 10 (1.3); Castro, I.F. 5 (1.3); Castro, R.M. 1289 (1.3); Conceição, A.A. 1122 (2.1), 2024, 2079 (1.3), 2225 (1.1), 2330 (1.3), 2450 (1.1), 2537 (1.3), 2541 (2.2), 2562, 2725 (1.3), 2735 (2.2), PCD2450 (1.3); Conceição, S.F. 50 (1.3), 442 (2.1), 551 (1.3); Costa, A.L. 317 (2.1), ALCB 493 (2.1), ALCB 495 (2.1), ALCB 2425 (1.3), ALCB 2426, ALCB 2739 (1.1), ALCB 19682 (2.1); Costa, G. 502, 576 (2.1), 1758 (1.3); Costa, L.C. 179 (2.1); Costa, M.A. 6 (1.1), 17 (1.3); Costa, S.M. 677 (1.3); Couto, A.P.L. 23 (1.3), 38 (2.1); Crepaldi, I.C. 8 (1.2); Cunha-Silva, S.L. 64 (1.1); Curran, H.M.R. 135, 165 , 205 (1.3); Davidse, G. 11663 (1.1); Eupunino, A. 512 (2.1); Fadigas, F.S. HURB 773 (2.1); Fernandes, D.S. 343 (1.3); Fernandes, M.F. 358 (2.1); Ferreira, M.C. 283 (2.1); Fiaschi, P. 1643 (1.3); Folli D.A. 993 (2.1); Fonseca, G.V. 174 (2.1); Fonseca, M.R. HUEFS 88584, PC 570 (2.1); França, F. 955, 1070 (1.3), 1450 (1.1), 1869 (1.2), 1920 (2.2), 1926 (1.3), 2142 (2.2), 2899 (1.3), 2901 (2.1), 3544 (1.3), 5150 (1.3); Freitas, J.G. 74 (1.2); Ganev, W. 1222 (1.2), 1765 (2.1), 2858 (1.3); Gasson, P. PCD 6026 (1.3), CEPEC74381 (1.3); Ginzbarg, S. 822 (1.1), 848 (2.1); Giulietti, A.M. 1662 (2.2), 1843, 1884 (1.3), 2074 (2.1); Gomes, F.S. 350 (1.3); Gonçalves, J.M. 163 (1.1); Gouveia, E.P. 02/83 (1.1), ALCB 21212 (1.3); Grupo Pedra do Cavalo 83 (1.3); Guedes, M.L. 12, 166 (2.1), 1381 (1.2), 1415 (2.1), 2690 (1.3), 4064 (2.1), 6975 (1.1), 8925, 8926, 11002 (1.3), 11514 (2.1), 11614 (1.3), 11922 (1.4), 12096 (2.1), 12900, 13110, 13237, 13550 (1.3), 13574 (2.2), 13970 (1.1), 14080 (1.3), 14507 (1.2), 14806, 15006 (2.1), 15760 (1.3), 16168, (1.1), 16255 (1.3), 16355 (1.1), 17023 (1.3), 17933 , 18058, 18447 (2.1), 19235, 19428, 19749 (1.3), 20078 (2.1), 20351, 20581, 20636, 20923, 21024a, 22451, 22801, 23075, 23854, 24353, 24668 (1.3), 24745 (2.1), 25655 (1.3), ALCB 20017 (2.1), R 218308 (1.3); Hage, J.L. 324, 482 (2.1), 1204, 1630 (1.3), 1636 (2.1), 1770 (1.3), 2064 (1.4), 2197, 2242 (2.1); Harley, R.M. 16213, 16509 (1.3), 16582, 17913, 20191, 22215, 22640 (2.1), 25293 (1.1), 54022 (2.2), 55565 (1.3), CFCR 6739 (2.1); Hatschbach, G. 44302 (1.1), 55189 (1.2), 66037 (1.3), 75290 (2.1), 78756 (1.3); Hummel, M. 12,116 (2.1); Jardim, J.G. 1246 (1.3), 1582 (2.1), 3580 (2.2); Irwin, H.S. 31636 (1.3); Jesus, N.G. 894 (1.1), 1351 (2.1), 1991 (1.3), HUEFS 144535 (2.1), ALCB 86826 (2.1), PC 721 (1.3); Jesus, R.J.A. 38 (2.1); Kallunki, J.A. 396 (1.2); Lima, A. 128 (2.1); Lima, C.T. 35 (2.2); Lima, J.C. 128 (2.1); Loureiro, D.M. 411 (1.3), 433 (2.1); Lucca, C.F. 17 (1.2); Macedo, G.E.L. 2379 (1.3); Machado, A.F.P. 1017, 1158 (1.1), 
1172 (1.2), 1402 (2.2); Machado, R.F. 391 (2.2), 581 (1.1); Maciel, J.R. 1140 (1.3); Magalhães, C.M. 243 (1.3); Mariano, K.R.S. 19 (1.3); Marques, N. 4 (2.1); Matos, G.S. 31 (2.1); Mattos-Andrade, P.E. ALCB 80869 (2.1), ALCB 80876 (1.1); Mattos-Silva, L.A. 2834 (1.3), 3257, 3338, 3392 (2.1); Mello-Filho, L.E.R. 2403 (2.1); Melo, E. 505 (2.1); 1454, 1497 (1.3), 1636, 1637 (2.1), 1903,2061 (1.3), 3012, 3102 (2.1), 4315 (2.2), 4379 (1.3), 4744 (1.1), 5296 (1.3), 5556 (1.1), 5575 (2.1), 5635 (1.3), 5734, 5806 (1.1), $5810,5851,5853$ (2.1), 5885, 5904 (1.1), 6033, 6034 (2.1), 6955, 7421 (1.1), 7584 (1.3), 10551, 10562, 10641 (1.1), 11472, 11480, 11606, 11650, 11890 (1.3), 12607 (1.1), 13203, 13501, 13547 (1.3), 13465 (2.1); Miranda, A.M. 4369 (1.3), 5511 (1.1); Miranda-Silva, E.B. 121 (1.3), 364,754 (1.1), 896 (1.3); Moraes, A.O. 36, 67 (2.1), 244, (2.2); Moraes, E.P.E. 5 (2.1); Mori, S.A. 11124, 11262 (1.3), 13725 (2.1); Nascimento, J.G.A. 82 (2.1); Noblick, L.R. 73, 2698 (1.1), 3195 (2.1), 3278 (1.3), 3707, 4171 (1.1); Nunes, T.S. 1225 (1.3); Oliveira, M. 4756, 4791, 4793 (1.3); Oliveira, R.P. 746, 1543 (1.3); Pacheco, L.M. 5, 62, 134 (2.1); Paiva, M. 2RGV, 18RGV (1.3); Paixão, J.L. 91, 1562 (1.3), 1599 (2.1), 1692 (1.3), 1855 (2.1); Passos Júnior, L.A. 245 (2.1); Paula-Souza, J. 5209 (2.1); Penguel. H.O. 10 (1.3); Perdiz, R.O. 55 (2.1); Pifano, D.S. 578 (1.3); Pinheiro, R.S. 83 (2.1), 408, 2009 (1.3); Pinto, G.C.P. 4 (2.1), 54/83 (1.3), 95 (2.1); Pirani, J.R. H 51331 (2.1); PROUFBA 151 (1.3); Queiroz, E.P. 212, 5363 (2.1); Queiroz, L.P. 41 (2.1), 1117, 1527, 1594, 1609, 1782 (1.3), 1830 (2.1), 3257 (1.2), 4859 (1.3), 5549 (1.1), 6447 (1.3), 7752 (2.2), 9297 (1.3), 9416 (2.1), 9420, 9459 (1.3), 9714 (1.1), 9716, 12089 (2.1), 12784 (1.3); Ramalho, F.B. 114 (1.1); Ramos, C.H.A. 124 (1.3); Rapini, A. 1207 (1.3); Rezende, S.G. 1655 (2.1); Ribeiro, A.J. 20 (1.3); ALCB 28578 (1.1); Ribeiro, T. 148 (2.1); Ribeiro-Filho, A.A. 181 (2.1); Rocha, D. 370 (1.3); Rocha, F.F. 81 (1.1); Roque, N. 651 (1.3), 4171 (1.1), FCO45, FCO64, FCO86, FCO142, FCO143 (2.1); Saar, E. 40 (1.3); Sambuichi, R.H.R. 23, 44, 73 (2.1); Sanaiotti, T.M. 346 (2.1); Santana, D.L. 240 (1.1), 538 (1.3); Sant'Ana, S. C. 212 (1.3); Santos, A.K.A. 125 (2.1); Santos, E.A. 57 (1.1); Santos, F.S. 217 , 472 (2.1); Santos, R.M. 1666, 1705 (1.3), 1728 (2.1), 1755 (1.1); Santos, T.S. 395 (1.2), 418 (1.3), 3501 (2.1), 3698 (1.3), 4428 (2.1), 4443 (1.3); Santos, V.J. 253 (1.3), 306 (1.2), 440 (1.1); Senna, L.R. 149 (2.1); Senra, L.C. 25 (1.2); Silva, E.M. 364 (1.1); Silva, L.A.M. 3257 , 3338 , 3392, 3510 (2.1); Silva, M. 41 (1.3); Silva-Castro, M.M. 330 (1.3), 346, 555, (2.1), 889, 927 (1.3); Silva, R.N. 1 (2.1); Siqueira-Filho, J.A. 2313 (1.3), 2341 (2.1), 2347, 3723 (1.3); Sobral, M. 5480 (1.3), 5915 (2.1); Soeiro, R. $50 / 89$ (2.1); Souza, E.R. 220 (1.1), 321 (2.1); Souza, F. 472 (2.1); Souza, L.G. 11 (1.3); Souza, P.P., CEPEC 37928, CEPEC 37975 (2.1); Souza, P.J.P. ALCB 10751, ALCB 10070 (2.1); Souza, R.S. 260, 500 (2.1), 511 (1.3), 616 (2.1), 817 (1.3); Strier, K.B. 613, 836 (1.4); Thomas, M.B. 588 (2.1); Thomas, W. W. 10405, 11323 (1.3), 11471 (2.1), 12390, 12522 (1.3), 13543, 13956 (1.2); Vieira, R.F. 1159 (1.3); Yoshida-Arns, K. 24 (1.3); Zehntner, L. R. R 39109 (2.1); R 73812 (1.3). 